\title{
EL JURADO: EXPRESIÓN DE LA SOBERANía POPULAR EN LA ADMINISTRACIÓN DE JUSTICIA EN LAS CAUSAS PENALES
}

\author{
VICTOR MANUEL TALAVERA HUETE \\ Master en Derecho Penal y Derecho Procesal Penal - UCA
}

\section{Introducción}

El jurado es sólo juez de los hechos y jamás del derecho, esta separación entre las cuestiones de hecho y derecho es lo que ha librado hacer del jurado el instrumento insustituible de una buena administración de justicia. Siendo un instrumento de participación, y para algunos, de democratización y de modernización de la administración de justicia; desde luego, no siendo el único.

La confianza en el jurado manifiesta la preocupación por proteger a los disidentes en juicios con extraordinarias connotaciones políticas. El jurado expresa una cierta concepción democrática de métodos de condena y absolución; así la resolución de las controversias penales, no brota de "jueces y verdugos", sino de los ciudadanos que quisieron una fuente de legitimidad democrática ${ }^{1}$.

1 En cambio, durante los primeros años del siglo pasado, esta institución fue criticada con mucha severidad y dureza, señalando: "Que el jurado no lleva a efecto una acción moralizadora y justa. Se le ha probado todo: su ignorancia, su miedo, su inconsecuencia, su parcialidad, etcétera, etc.; el Jurado no reúne las condiciones que debe adornar a todo Juez. De dicho "Tribunal del terror", como le llama Mittermaier, se cuentan hasta anécdotas y... que le favorecen muy poco. Entre ellas merece especial mención la de aquel Jurado que siempre respondía sí. Preguntado por qué así lo hacía, contestó que era ¡porque no sabía escribir la palabra no! Es indudable que el Jurado tiene que seguir las costumbres de los lugares donde juzga. En Italia absuelve a los que cometen crímenes con armas blancas; en América a los ladrones y estafadores. En casi todo el mundo, el infanticidio para ellos no es un delito, menos en Bretaña, donde es muy raro". Véase Canalejas Rubio, José. La Pena de Muerte. Biblioteca de la Facultad de Derecho de la Universidad de Sevilla. Edición digital jabyn@us.es, págs. 36/37. 
Historiadores nicaragüenses refieren que en nuestro derecho precolombino existió el Tribunal de Jurados para administrar justicia en materia penal, con los Monéxicos, o Consejo de Ancianos. Esto pudo haber ejercido influencia en la concepción de nuestro sistema de jurados, pero no considerarse propiamente como un antecedente.

Nicaragua, como pocos países latinoamericanos, ha atravesado por difíciles procesos, incluido un período de guerra y una posterior transición, que han marcado profundamente a la sociedad y su sistema político. Necesariamente ello se ha visto reflejado en su sistema de justicia.

Años atrás la justicia penal era inquisitiva y las normas que regulaban el proceso eran de 1879. Hoy contamos con un Código moderno basado en el principio acusatorio que data del 2001.

Desde la Constitución Política de 1824, Nicaragua ya tenía jurado, aunque se implantó mucho después. Siendo un jurado corrupto e inútil, esgrimían unos, que no cumplía ninguna de las misiones para las que fue ideado, ni que satisfacía el mandato establecido en el Artículo 166 de la Carta Magna, concretado como derecho del ciudadano en su Art. 34.3, y desarrollado en el derogado Código de Instrucción Criminal de 1879 .

La experiencia de los tribunales de jurado en Nicaragua, ha mostrado que tiene sus riesgos, pero es preferible asumirlo para no apartar al pueblo de la participación y al hacer un balance histórico, el saldo es ventajosamente positivo a lo largo de más de una centuria de jurados en Nicaragua. El jurado es un derecho de la ciudadanía para participar en el proceso judicial que debe preservarse.

Actualmente están emergiendo corrientes reformistas tendientes a delimitar el número de supuestos en que debe intervenir el jurado, basándose que al resolver el Juez técnico conlleva a la aceleración de la administración de justicia y a la reducción de costos por razones económicas en la integración del Tribunal de Jurado; que se trata de evitar la coacción y el chantaje del crimen organizado a los miembros del jurado y sus familias. Sin embargo, y penosamente para la comunidad y los operadores de justicia, algunos miembros de los tribunales de justicia de la República se han visto involucrados en fallos y resoluciones favorables al crimen organizado. 
A nuestro juicio estas reformas no solamente deben incidir en ese ámbito, sino en otros, tales como: un procedimiento más eficaz en las listas debidamente depuradas de ciudadanos hábiles entregadas por el Consejo Supremo Electoral a la Corte Suprema de Justicia para ser candidatos a jurados, las cuales podía hacerse una sola lista para dos o tres años, en lugar del actual que es año con año, ya que al momento de la selección aleatoria y citación de los candidatos a jurados resulta(n) que algunos de éstos no saben leer y escribir, o han fallecido o cambiado de domicilio, o se encuentran comprendidos dentro de las prohibiciones y causales para el ejercicio de la función; mejoría en la retribución o dieta por el desempeño de la función de jurado y proveer lo necesario para asegurar la manutención, alojamiento y transporte para el desplazamiento de su domicilio o centro de trabajo al lugar del jurado; estricto cumplimiento de la compensación de la dieta al concluir las labores, ya que se ha vuelto costumbre el no pago inmediato a quienes cumplieron su deber ciudadano de impartir justicia; ampliación del período para participar como jurado, que no sea de un año; reducir el numero de personas inhábiles por naturaleza institucional o profesional, e incluso, desestimar la excusa a quienes invocan la llamada objeción a ser jurado, como algunos religiosos.

En una hipotética reforma tendiente a reducir el número de miembros que no pueden desempeñar la función del jurado, deben suprimirse de las prohibiciones, contempladas en el Artículo 44 del Código Procesal Penal de la República de Nicaragua², Ley No. 406/01, los estudiantes o profesionales en Derecho; los miembros del Ejército Nacional y de la Policía Nacional, salvo aquellos que no ostenten grados de mando o que de una u otra manera hayan tenido vinculación directa con el caso a ser sometido al conocimiento del jurado. Asimismo, dentro de las causales de excusa, señaladas en el artículo 46 del mismo cuerpo de leyes, los que realicen trabajos relevantes de interés general. En mi criterio no debe haber excusa para prohibir o eludir que $\mathrm{X}$ o Y ciudadano desempeñe el cargo de jurado, ya que éste es un deber, consagrado en la Constitución Política. Además, cada quien actúa conforme su propia conciencia y su propio criterio, independientemente de su nivel académico para decidir, sin dejarse influenciar por quienes sean estudiantes o profesionales del Derecho, o miembros de la Policía o del Ejército, en el supuesto, éstos integraran un jurado, como igualmente no lo integrasen.

$\overline{2 \text { Abreviadamente }}$ CPP. 


\section{II.Nacimiento del Jurado. Evolución histórica. Institucionalidad del Jurado en Nicaragua}

\section{Nacimiento del Jurado}

El doctor Manuel Ossorio y Florit, en su obra, define el Jurado, como "Tribunal constituido por ciudadanos que pueden o no ser letrados y llamado por la ley para juzgar, conforme a su conciencia, acerca de la culpabilidad o de la inocencia del imputado, limitándose únicamente a la apreciación de los hechos, sin entrar a considerar aspectos jurídicos, reservados al juez o jueces que, juntamente con los jurados, integran el tribunal"3.

Como un preámbulo sobre el origen del Jurado, la Comisión Especial nombrada por las Cortes Españolas de 1821, encargada de redactar el Código de Procedimiento Criminal, se pronuncio en el sentido de señalar la conveniencia de implantar el juicio por jurados, razonando así: " $E l$ origen del jurado, establecimiento amigo del hombre y de su libertad, se pierde en el ocaso del tiempo. Quizá nació con la sociedad civil y fue anterior a las leyes escritas. La historia nos los ofrece como inseparable de los pueblos libres y del sistema representativo. Grecia y Roma, y todos los pueblos que han tenido algún respeto a sus libertades, lo han reconocido, y lo han conservado más o menos puro en razón del mejor o peor estado de su libertad política. Degenera y se vicia con el poder absoluto; se perfecciona y fructifica con la fuerza e independencia del Poder Judicial......"4.

Cita el Doctor Salvador Guillén, en su tesis doctoral, que en 1820 reuniéronse las Cortes en España, sosteniendo la necesidad y urgencia del establecimiento del Jurado. Que era según se dijo en el Congreso "Baluarte de la inocencia y terror del crimen y que es por si solo bastante para ilustrar y dar moralidad a las naciones".

Como instrumento de defensa de la libertad y la democracia esta Institución del Jurado nació como medio de frenar el absolutismo

3 Diccionario de Ciencias Jurídicas, Políticas y Sociales, Argentina, Editorial Heliasta, S.L.R., 2004, pág. 549.

4 AGUILAR, Marvin. "Breve reseña de historia antigua o aborigen de Nicaragua". El Jurado en Nicaragua: Una Valoración Crítica desde la Perspectiva del Derecho Comparado, Imprenta UCA, Managua, 2002, pág. 122.

5 VALLE PASTORA, Alfonso, "Tribunal de Jurados", Managua, Impreso en los Talleres de la Imprenta Nacional, 1975, pág. 7. 
real en los juicios penales, y de que el Jurado fue adoptado como una consecuencia del sistema democrático en casi todas las legislaciones desde mediados del siglo XIX hasta principios del siglo XX.

Agregan que nace en Grecia ${ }^{6}$ y Roma, ambas republicanas; $y$ que el juicio a Sócrates es el mejor ejemplo de la existencia de un verdadero juicio por jurado en la antigua Atenas. Dado que en este proceso el juicio fue oral; intervinieron abogados acusadores y un defensor del acusado que Sócrates, contra el consejo de sus amigos insistió en ser él mismo; la intervención de jueces no profesionales en la declaración de inocencia o culpabilidad de un encausado; y el fallo de la Asamblea que fue condenatorio a la pena máxima ${ }^{7}$.

Otros, señala el jurista Marvin Aguilar ${ }^{8}$, lo consideran en la Inglaterra medieval y en ésta el Assize ${ }^{9}$ de Clarendon, dictado en 1166 por Enrique II. Los acusados, a través de este sistema, eran sometidos a la prueba de ordalía ${ }^{10}$.

Este sistema cambió hacia el siglo XIV y la ordalía fue sustituida por el juicio por jurados. Por un estatuto de 1352 el jurado fue dividido en dos: el juicio se llevaba a cabo ante un jurado de doce personas y la acusación provenía de un jurado de veinticuatro personas escogidas en todo el condado, especialmente entre los caballeros.

En 1368 Eduardo III expandió esta práctica a todos los condados del reino, quedando así establecido en doce el número de los jurados, desconociéndose por qué se eligió esa cantidad, pero probablemente era lo suficientemente grande como para transmitir representatividad,

6 Iván Escobar Fornos, en su discurso inaugural del Foro sobre "El Jurado en Nicaragua: Una valoración crítica desde la perspectiva del Derecho Comparado" (2002). En el libro "El Jurado en Nicaragua:......" Managua, Imprenta UCA, 2002, pág. VIII: "Por su peculiar concepción política de que el poder residía en la soberanía ciudadana, establecieron diferentes tipos de jurados: los Heliastas, o de Helion porque sesionaba en la plaza bajo la luz del sol. Se componía de un gran número de personas, de 500 o más cuando todas sus secciones se unían para el juicio. El tribunal de los efetas estaba compuesto por 51 miembros y solo juzgaba homicidios involuntarios o no premeditados".

7 Aguilar, Marvin. "Breve reseña de historia...” Op. cit., pág. 120.

8 Aguilar, Marvin. “Breve reseña de historia...”Op. cit, pág. 120.

9 Se trataba de un estatuto u ordenanza por medio del cual el Rey pretendía apartar a los barones feudales de la administración de justicia. El Assize preveía un sistema inquisitivo llevado a cabo en cada comunidad por un panel de 12 personas, a quienes se les tomaba juramento y se les imponía la obligación de acusar ante los jueces de paz itinerantes del reino o el sheriff a todos los que presumiblemente hubieren cometido un delito.

10 Juicios de Dios, fue una forma brutal de enjuiciamiento por medio de la cual se sometía el acusado a diversas pruebas de resistencia física al tormento, que en caso de superarlas era considerado inocente. 
Revista de Derecho

confianza e imparcialidad y al mismo tiempo lo suficientemente pequeña como para actuar con eficacia.

Con el devenir del tiempo el jurado comenzó a obtener mayor grado de independencia, adoptando la costumbre de recibir la declaración de los testigos ante sus propios estrados en forma privada y los Tribunales dejaron de exigirle que fundamentara las razones de rechazo de una acusación.

En la Nicaragua prehispánica, particularmente en los pueblos más civilizados, la justicia se administraba regularmente por Tribunales integrados de individuos escogidos entre los miembros de la aristocracia a quienes no se podía separar del cargo mientras lo desempeñaran bien. En cambio, en otras tribus, la justicia era ejercida por el cacique, a quien denominaban TEYTE. Sin embargo, en esta etapa histórica, no hubo ninguna institución o costumbre que se asemejase al juicio por jurado.

Durante la época colonial que España dominó en gran parte de América los órganos de la justicia no constituían un poder independiente. Las facultades y atribuciones de naturaleza judicial eran ejercidas por órganos que participaban de carácter judicial y político; así también las de naturaleza política eran desempeñadas por órganos políticos y judiciales. Además, existían muchos tribunales especiales ${ }^{11}$.

\section{La finalidad de la administración de justicia era la de hacer prevalecer el} bien común, el cual, no era ni el bienestar de la mayoría, ni el beneficio

11 En la Primera Constitución Política del Estado de Nicaragua, del 8 de abril de 1826, en su artículo 116, se estableció: "Todo habitante deberá ser juzgado por el juez ó tribunal competente, establecido con autoridad por la ley; y no podrán formarse comisiones, ni tribunales especiales para conocer en determinados delitos, ni para cierta clase de ciudadanos;......" Igualmente en las Cartas Magnas de 1858, 1893, 1905 y 1913, se consagró esta garantía individual de la persona humana. Sin embargo, en 1979, conforme Decretos-Ley, dictados por la Junta de Gobierno de Reconstrucción Nacional de la República de Nicaragua, fueron creados los TRIBUNALES ESPECIALES DE EMERGENCIA, para conocer y resolver los conflictos o las violaciones estipuladas en la Ley Sobre el Mantenimiento del Orden y Seguridad Pública y la Ley de Emergencia Nacional; igualmente, los TRIBUNALES ESPECIALES de Primera Instancia y de Apelación, con el objeto de conocer los delitos tipificados en el Código Penal vigente, cometidos por militares, funcionarios y empleados civiles del régimen anterior, y cualquier otra persona que amparada por sus relaciones con ellos, hubiera participado en la comisión de los mismos, ya sea como autores, cómplices o encubridores, y que se encuentren detenidas, o fueran habidas durante la vigencia de los mismos. Estos tribunales fueron disueltos en 1981 y su competencia asumida, sin modificación ni limitación alguna, por los tribunales penales ordinarios. Pero, irónicamente, los constituyentistas de 1987, a pesar que en el Preámbulo de la Constitución Política de la República de Nicaragua, evocaron la institucionalización de las conquistas de la Revolución.... y el respeto absoluto de los derechos humanos; establecieron en las disposiciones finales y transitorias, específicamente en el artículo 199, un hibrido con la existencia, además del Poder Judicial, de los TRIBUNALES ESPECIALES, quienes seguirían funcionando al entrar en vigencia esta Constitución, mientras no pasaren bajo la jurisdicción del Poder Judicial. Véanse Decretos Nos. 34, 185 y 643, del 7 de agosto y 29 de noviembre de 1979, publicados en La Gaceta Nos. 4, 75 y 41, del 28 de julio de 1979, 5 de diciembre de 1979 y 20 de febrero de 1981, respectivamente. 
de una clase, ni el predominio absoluto de la raza española, mediante la aplicación de las normas adecuadas para que todos se sintieran partícipes de los mismos derechos, beneficiaros de las mismas medidas de beneficio colectivo, mediante su justa aplicación. La armonía y el equilibrio debían dar a todos en la comunidad los derechos que le correspondían justamente.

En 1511 fue creado el Consejo de Indias, con sede en Madrid, el cual a su vez era Cámara de Consulta, Asamblea Legislativa, Tribunal de Justicia, Tribunal de lo Contencioso Administrativo y Tribunal Administrativo. Como Tribunal de Justicia conocía en alzada de las sentencias dictadas por las Audiencias. Éstas se crearon a fin de resolver las controversias, tanto de orden civil como penal y sus miembros recibieron el nombre de oidores, los cuales estaban investidos de alta autoridad y elevada consideración.

Para Centroamérica fue creada en Barcelona, España, por Carlos V, la primera audiencia en 1542, conocida como la Audiencia de los Confines y la cual conocía de todos los juicios civiles y criminales pendientes y de los que en lo sucesivo se promovieran. Además, sirvieron para controlar los abusos cometidos por Virreyes, Capitanes Generales, Gobernadores; y conocían de los recursos de apelaciones de las resoluciones dictadas por Gobernadores y Alcaldes mayores. Estos ediles, según su ley creadora, tenían funciones exclusivamente judiciales, equivalentes al de un Juez de Distrito, en el fenecido sistema inquisitivo, quien debía hacer personalmente todas las investigaciones del caso hasta establecer la culpabilidad del procesado.

En la época colonial no hubo en Nicaragua institución alguna en el Derecho Penal que se asemejase al juicio por jurados, al igual que en el período prehispánico. No contemplándose en el Derecho Indiano el origen del Tribunal de Jurados en Nicaragua ${ }^{12}$.

Se instituye por primera vez en 1808, en la Constitución de Bayona, promulgada el 6 de julio de ese año, la cual regía en España y en la Provincia de Nicaragua, al establecer: "El proceso criminal será público.

12 Antes de la Colonia funcionaban los monéxicos que eran los consejos para impartir justicia, su decisión tenía sanción social y las decisiones eran apoyadas por toda la comunidad, más o menos un proceso similar al de nuestras comunidades indígenas de la costa Caribe de la Nicaragua de hoy. 
Revista de Derecho

En las primeras Cortes se tratará de si se establece o no el proceso por jurado"13.

En cambio, la Constitución Liberal de Cádiz de 1812, que influyó marcadamente en la independencia de América y de Centroamérica, no estipulaba nada respecto del establecimiento de jurados, sino únicamente "si con el tiempo creyeren las Cortes que conviene haya la distinción entre Jueces de Hechos y de Derecho, lo establecerán en la forma que juzguen conveniente"14.

Concretamente, bajo la vigencia de estas Cartas Magnas, no se dictaron leyes ordinarias que diesen nacimiento al jurado.

Posteriores Constituciones tampoco lo establecieron. Fue bajo la vigencia de la Constitución de 1826, la cual no contenía disposición expresa acerca del jurado, que se estableció en Nicaragua el procedimiento del juicio por jurado, por Decreto del 14 de Mayo de 1835 y reglamentado en el Decreto del 29 de Noviembre de 1837.

\section{Evolución histórica}

La evolución histórica de la institución del JURADO en Nicaragua viene a resaltar que su introducción no se produjo sino hasta el siglo XIX, como consecuencia de las corrientes ideológicas derivadas de las transformaciones político-sociales que originó la Revolución francesa, la que fue basamento, y otra fuente, la Constitución de Bayona de 1808 y luego la Constitución de Cádiz de 1812. Ambas no lo implantan de manera directa, dejándolo para una situación de futuro. El primer texto constitucional señala: “........si sería procedente o no establecer el proceso por Jurado"15. Y el segundo, decía: "Si con el tiempo creyeren las Cortes que conviene haya distinción entre los jueces del hecho y del derecho,...."16.

Es instituido, como resaltaba, en la de Bayona, la cual regía a la Provincia de Nicaragua por ser colonia española. Sin que, al amparo de la misma, ni de la Cádiz, se dictaran leyes ordinarias que establecieran los Tribunales de Jurado.

13 Art. 106 Constitución de Bayona.

14 Art. 307 Constitución de Cádiz.

15 Art. 106 Constitución de Bayona.

16 Art. 307 Constitución de Cádiz. 
Así también, la Constitución Federal de Centroamérica de 1824, dispuso: ".......tan luego como sea posible, establecerán el sistema de Jurados". Sucesivas Constituciones no hablan nada acerca del o de los Jurado(s) ${ }^{17}$.

El procedimiento del juicio por jurado fue establecido en Nicaragua por Decreto del 14 de Mayo de 1835, siendo Jefe de Estado don José Zepeda. Ley ésta reglamentada por Decreto del 29 de Noviembre de 1837, en donde ejercía de defensor a falta de nombramiento del reo, el Sindico menos antiguo de la municipalidad de la Cabecera del Distrito, correspondiéndole la acusación al Síndico más antiguo de la misma comprensión judicial.

Fungiendo como Director del Estado don José León Sandoval, en 1845, se suspendieron los efectos de la Ley de Jurados. Restableciéndose luego por Ley del 7 de Junio de 1877, relativo a la formación de listas de jurados; su composición; reglas para deliberar; ámbito de competencia; derecho a la defensa e intervención del procesado; papel de la víctima ante el Tribunal de Jurado; la práctica de los distintos medios de prueba; el veredicto y los medios de impugnación; rol del Juez frente al Tribunal de Jurado.

En el Proyecto de Constitución Política de 1854, se establecía el jurado para los delitos de imprenta.

En 1879 se promulga el Código de Instrucción Criminal.Con posterioridad a su vigencia se realizan reformas al jurado, entre ellas la Ley del 5 de Septiembre de 1883, que establecía nuevos requisitos para ser electo jurados; quiénes no podían ser electos; composición del Tribunal; juramento; $y$, veredicto.

Las disposiciones de dicho cuerpo de leyes relativas al jurado fueron derogadas por la Ley de Jurados del 21 de Septiembre de 1897, cuyo articulado se incorporó a dicho Código. Realizándose reformas sustanciales en algunos aspectos y en otros, se mantuvieron las mismas de la anterior Ley de 1877, la que se promulgó bajo la vigencia de la Constitución Política de 1893.

17 Constituciones Políticas de Nicaragua de 1826 y 1838. 
Con sus reformas estructurales la Ley de Jurados de 1897, a través de leyes y decretos ${ }^{18}$, tendientes a adecuarla a los cambios políticos y sociales, el Tribunal de Jurados permaneció inalterable en Nicaragua desde ese año hasta 1988, en que por Ley No. 37 "LEY DE REFORMA PROCESAL PENAL”, del 18 de abril de 1988, se estableció que ningún tipo de delito será sometido al conocimiento y veredicto del jurado.

Hasta la Reforma Procesal Penal de 199l, vigente por Ley a partir de 1992, se reinstaura por segunda ocasión el jurado, estableciéndose: "Los delitos comunes que merezcan penas más que correccionales deberán ser sometidas al conocimiento del Tribunal de Jurados".

A lo largo de la historia desde que se instituyó el jurado, aún cuando Nicaragua no se regía por una Constitución como Estado libre, soberano e independiente, únicamente en dos ocasiones se ha suprimido: a) Desde 1845 hasta 1877, por un lapso de 32 años; y, b) de 1988 a 1992, por un período de 4 años ${ }^{19}$.

En esos períodos históricos del Tribunal de Jurados se estableció que están sujetos al juicio por jurado, en algunos casos, todos los delitos comunes $^{20}$; en otros, los delitos comprendidos en el Libro Segundo del Código Penal y las faltas que le sean conexo ${ }^{21} ;$ y en otros, los delitos que merezcan pena más que correccional; con las correspondientes excepciones. En cambio, en 1974, por las circunstancias políticas de ese entonces, al igual que en 1982, el ámbito de competencia se redujo. Sin embargo, en 1979 al surgimiento de un nuevo orden político, este ámbito se amplió.

Con la Reforma Procesal Penal de 1991 y la Ley de Reformas al Código de Instrucción Criminal de 1993, no se hacen exclusiones, debiendo ser sometidos al conocimiento del Tribunal de Jurados todos los delitos comunes que merezcan penas más que correccionales.

En la Ley No. 285, se establece que los delitos contemplados en ésta, no serán sometidos al conocimiento del Tribunal de Jurados ${ }^{22}$.

18 Leyes de 1908, 1913 y 1914; y Decretos 1917, 1959, 1963, 1974, 1979, 1982 y 1988.

19 En la República de Argentina transcurrieron 100 años en instaurar la oralidad y llevan 152 años sin jurado; y en España la reinstauración del jurado se produjo más de 16 años después de la vigencia de la Constitución, al aprobarse la Ley Orgánica del 22 mayo 1995, del Tribunal del Jurado.

20 Ley de Jurados de 1877.

$21 \quad$ Ley de 21 de Septiembre de 1897.

22 "Ley de estupefacientes, sicotrópicos y otras sustancias controladas; lavado de dinero y activos provenientes de 


\section{Institucionalidad del Jurado en Nicaragua}

A inicios del siglo XIX Nicaragua era una Provincia de España y se regía por la Constitución, Código de leyes civiles y criminales, Reglamentos y Ordenanzas de la nación española.

Por la Constitución del Estado, conocida como Constitución de Bayona, promulgada en la ciudad de Bayona, el 6 de julio de 1808, por don José Napoleón Bonaparte, Rey delas Españas y delas Indias, seinstitucionaliza constitucionalmente el jurado, estableciendo en la citada norma: "El proceso criminal será público. En las primeras Cortes se tratará de si se establecerá o no el proceso por Jurados”23.

Con base en esa disposición, y la situación jurídica-política de Nicaragua, se consagra el inicio de los principios constitucionales en que se fundamenta la institución de Jurados en nuestra patria.

Conforme la Constitución de Cádiz de 1812, -la que al igual que la de Bayona rigió en España y en Nicaragua- se dispuso: "Si con el tiempo creyeren las Cortes que conviene haya distinción entre los jueces del hecho y del derecho, la establecerán en la forma que juzguen conducente"24.

Ambas normas constitucionales asumen una posición cautelosa, sin implantarlo de manera directa y dejándolo para una situación de futuro.

En la Constitución Federal de Centroamérica de 1824, se estableció, en el Título atingente a las garantías de la libertad individual, Art. 154: "Las Asambleas, tan luego como sea posible, establecerán el sistema de jurados".

Sin embargo, las Constituciones Políticas de 1826 y 1838, siendo Jefe de Estado, don Juan Arguello y Supremo Director, don José Núñez, respectivamente, no contienen disposiciones expresas acerca del jurado. Igualmente con la Constitución de 1858, bajo el Gobierno del general Tomás Martínez, pero en ésta se disponía que: "Después de la confesión no puede prohibirse al procesado la comunicación con persona alguna, 


\section{Revisla de Perecho}

y el juicio es público". Quizás pretendían los diputados constituyentistas de la época, con esta disposición, establecer el jurado.

Durante el mandato del general Zelaya, se estableció el jurado en el artículo 63 de la Constitución de 1893, al disponer que no se imponga ninguna pena más que correccional, sin que preceda la declaración del jurado.

En la reforma de 1896, la redacción a dicho artículo cambió, así el jurado fue destinado a conocer únicamente de los delitos comunes, excluyendo los de orden político y militar. El texto se mantuvo igual en la reforma constitucional de 1905.

Bajo la vigencia de esta Constitución se emitió la Ley de Jurados, del 21 de Septiembre de 1897, vigente hasta el año 1988 en el Código de Instrucción Criminal, el que se reformó mediante el Decreto No. 37, Ley de Reforma Procesal Penal, la cual en su Art. 16 terminó por completo con la institución del Jurado al establecer que ningún tipo de delito seria sometido al conocimiento de éste.

La Constitución Non Nata de 1911 contenía una disposición análoga en materia de jurados ${ }^{25}$. Y la Ley fundamental de nuestra Nación de 1911, promulgada bajo el mandato de Adolfo Díaz, mantuvo el mismo sentido sin mayores cambios; igualmente la de 1913.

Siendo Presidente dela República, Anastasio Somoza García, se promulgó la Carta Magna de 1939, la que en el artículo 46, no se establecía con carácter imperativo como en las anteriores, sino que fue hasta la de 1948. Señalándose en aquella que la ley podía establecer el juicio por jurado en causas criminales o civiles; incorporándose el jurado para causas civiles ${ }^{26}$. Modificándose en la Constitución de 1948, durante el Gobierno de don Víctor Manuel Román y Reyes, que lo limitó sólo a las criminales.

25 Art. 65

26 En este sentido Valle Pastora, Alfonso.”Tribunal de...” Op. cit., pág. 6: "Referente al Jurado en materia civil, en nuestro Código de Procedimiento Civil en su Art. 991 y siguientes reglamenta el jurado para asuntos civiles, pero es de escasísima aplicación en la vida práctica, ya que como muy bien dice el Dr. Ramiro Granera Padilla en su Manual de Derecho Procesal Penal, "En los asuntos civiles cuando las partes desean resolver sus diferencias al margen de los Tribunales comunes, recurren a los Árbitros o amigables componedores, quienes resuelven sujetándose únicamente a lo que su prudencia y equidad les dicta”. 


\section{Recissa de Perecho}

En la Constitución de 1950, promulgada bajo la presidencia de Anastasio Somoza García, se estableció para aquellas causas criminales con penas más que correccionales. Y en la de 1974 se establecía el juicio por jurado por mandato de ley. El Estatuto de Derechos y Garantías de los Nicaragüenses de 1979, mantuvo el mismo criterio. La Carta Magna de 1987, vigente a la fecha, no lo estableció, sino que con posterioridad en las reformas de 1995, la cual en el artículo 34, en el Titulo IV, Capítulo I, Derechos Individuales, establece el juicio por jurados en los casos determinados por la ley.

Tras estas breves reseñas de las disposiciones constitucionales que han regido a través de los años, se aprecia que la historia nacional no refleja una costumbre jurídica uniforme, sino que la regulación de los casos que conoce el jurado ha variado en cada legislación. En la actual Constitución Política se dice que la ley regulará los casos en que intervendrá el jurado. Siendo la única excepción la de 1939, que incorpora el jurado para causas civiles.

\section{Composición. Fortalezas y Debilidades. Jurados interactivos y escabinos, sus viabilidades en Nicaragua. Reformas al sistema del Jurado.}

\section{Composición}

Todo procesado tiene derecho en igualdad de condiciones a ser sometido a juicio por jurados, reza la disposición penal. Agregando dicha disposición, y vinculada constitucionalmente, que es deber ciudadano participar en el proceso penal como miembro de un jurado cuando sea requerido ${ }^{27}$.

Históricamente en Inglaterra, siglo XIV, el jurado fue dividido en dos: el juicio ante un jurado de 12 personas y la acusación provenía de un jurado de 24 personas. Estableciéndose en 1368 en 12 el número de jurados, sin determinarse las razones del porqué se eligió esa cantidad.

La ley que institucionalizó el jurado en Nicaragua en $1835^{28}$, no determinaba específicamente su composición, si no que establecía que enseguida se procederá a sacar de la urna 21 cédulas de cuyos nombres 
formará el Escribano o Secretario Municipal una lista que publicará ante el Juez, reo, defensor, Síndico y Fiscal. Listas que aún predominan, con sus variables.

Desaparece la tradicional atribución de las municipalidades de las cabeceras de distritos judiciales de elaborar, en la presencia de los diferentes funcionarios las listas de jurados ${ }^{29}$. El CPP, artículo 47, establece que el Consejo Supremo Electoral en la primera quincena del mes de noviembre de cada año entregará a la Corte Suprema de Justicia los listados de ciudadanos hábiles para ser candidatos a jurados, radicados en el municipio en que se encuentra ubicada la sede del distrito judicial correspondiente.

$\mathrm{Al}$ reinstaurarse el jurado en 1877, después de haberse suprimido, su composición fue de nueve miembros, para lo cual se desinsaculaban nueve jurados los que integrarían el Tribunal y cinco más como suplentes para las reposiciones que debiesen hacerse, de conformidad con la ley. En posteriores reformas se compuso de cinco; luego varió al pasar a siete miembros en la reforma de 1908.

Sin embargo, en la Ley de Jurados de $1913^{30}$, promulgada bajo la vigencia de la Constitución Política de 1911, el número de miembros que compondrían el Tribunal de Jurados sería el mismo; pero para los delitos de traición, parricidio, asesinato atroz, incendio de morada con muerte y robo con homicidio, el Tribunal se compondría de nueve. Según criterio de la Corte Suprema de Justicia, respecto a la disposición legal antes enunciada, la intención del legislador al dictar el artículo 9 de la Ley referida, fue visiblemente que el jurado de nueve personas tuviera lugar tan solo para los casos en que cupiera aplicar la pena de muerte; y al no estar reglamentada ella, la integración de jurados debe hacerse con siete personas.

En otra reforma, la de 1979, se incorpora al Tribunal de Jurados al Juez de la causa o el que deba sustituirle en su caso. Posteriormente, y al volver a restaurarse el jurado en 1992, este Tribunal se conformó de

29 Alcalde y los Concejales, dos Comisionados de la Corte Suprema de Justicia, Procurador de Justicia o un Delegado de éste, Jueces de Distrito de lo Criminal, el Presidente de la Directiva de los Consejos Regionales Autónomos o su Delegado, y el Coordinador Regional, o su Delegado, de las Regiones Autónomas de Atlántico. Según Art. 6 Ley No.164 "Ley de Reformas al Código de Instrucción Criminal", La Gaceta No. 235, 13 de diciembre de 1993.

30 Conocida como "Ley de Llamamiento de Jurados", del 29 de octubre de 1913. 
cinco miembros, cuatro jueces legos y un juez de derecho designado por el juez de la causa. Éste no es parte de la lista general de los candidatos a jurados, ni es desinsaculado pero si debe ser judicial ${ }^{31}$.

En ese período desde la instauración del jurado en el sistema inquisitivo hasta la abolición del mismo con el nacimiento del principio acusatorio, a través del CPP, su composición e integración fue variable, inicialmente con jueces de hecho y finalmente con jueces legos y de derecho o técnicos, que pudiera haber sido concebido como un incipiente modelo escabinado: compuesto por jueces técnicos y legos en derecho que conocen tanto del hecho como del derecho; al igual que la histórica disposición consagrada en la Constitución de Cádiz de 1812. Pero no un puro modelo escabinado, al cual se aspira llegar y es el que esta predominando en la mayoría de los países europeos.

Hubo una época que seis jurados debían de estar de acuerdo para que hubiese veredicto, cuando el Tribunal era de nueve; en otra, cuando era de cinco para dictar resolución al menos cuatro debían de estar de acuerdo. Al variar la composición de cinco a siete miembros, el veredicto se constituía con mayoría simple. Finalmente, en la última reforma, se estableció que cuatro votos en un mismo sentido constituían veredicto ${ }^{32}$.

Conforme las disposiciones del CPP, el Tribunal de Jurados estará compuesto por cinco miembros titulares y uno suplente, siendo éstos personas legas en derecho, es decir, por ciudadanos que no tengan conocimientos especializados en la materia y reúnan los requisitos establecidos en el Articulo $43 \mathrm{CPP}$. En caso, uno de los miembros por causa justificada no pudiere continuar en el juicio, se incorporará al suplente siempre que haya estado presente desde su inicio. Pero al faltar otro, se podrá continuar con la presencia de los otros cuatro de los miembros.

31 Moreno Castillo, María Asunción. “Aspectos Generales del Tribunal de Jurado en Nicaragua. Funcionamiento y Consecuencias del Modelo Vigente”. El Jurado en Nicaragua: Una Valoración Crítica desde la Perspectiva del Derecho Comparado, Imprenta UCA, Managua, 2002, pág. 175.

32 Cita George P. Fletcher, en su obra "La Justicia impartida por el pueblo", pág. 286, sobre el caso de un acusado por pornografía con un jurado de cinco miembros en el Estado de Georgia, Estados Unidos de América, que "El Tribunal Supremo, a partir de la decisión de 1970 que permitía la reducción del número de miembros, evaluó un buen número de estudios sobre el Jurado. Los estudios realizados sobre las deliberaciones de los miembros indicaban que a medida que el número decrecía, el riesgo de condena de un inocente aumentaba; pero también se comprobó que cuanto más reducido es el Jurado, menor es el riesgo de que el culpable se libre de la condena. Por tanto, reducir el número de personas deliberando en el Jurado conlleva un problema (condenar al inocente) y un beneficio (condenar al culpable)". 
Para la escogencia ${ }^{33}$ de los cinco jurados, el Juez de Distrito de la causa en sesión pública celebrada dentro de las 24 horas anteriores al inicio del juicio, siguiendo un procedimiento de selección aleatoria escoge un número suficiente de candidatos a miembros de jurado, de acuerdo al numero de partes en el proceso; el cual en ningún caso deberá ser menor de doce personas ${ }^{34}$.

En el antiguo y fenecido sistema inquisitivo el juez de derecho era miembro del Tribunal de Jurados ${ }^{35}$, lo que indudablemente conllevaba a la pérdida de independencia del jurado, ya que éste con su presencia y participación, aún cuando los legos en derecho tuvieran su propio criterio, orientaba la discusión e influía sutilmente en el veredicto ${ }^{36}$. Actualmente el Juez preside el juicio, no el jurado, resuelve todas las cuestiones legales que se susciten e instruye al jurado, al momento de su finalización; pero no es miembro del mismo y por ningún motivo puede estar presente en la deliberación y votación ${ }^{37}$.

El veredicto se hará al menos con cuatro votos coincidentes que expresen el pronunciamiento acerca de la culpabilidad o no culpabilidad del o los acusados. Sin embargo, en caso no se llegase a un veredicto en un plazo de 72 horas, será disuelto y se convocará a nuevo juicio con nuevo jurado. Pero si en el segundo juicio, vencido el plazo, tampoco se logra veredicto, el Juez dictará sentencia absolutoria ${ }^{38}$.

33 En una de las modificaciones al articulado del fenecido Código de Instrucción Criminal en 1959, sobre los jurados, en lo relativo, entre otros, a la escogencia de éstos, se estableció: "En la escogencia de los jurados se hará una selección concienzuda incluyendo solamente a personas que merezcan confianza por su honradez e idoneidad, entendiéndose por tales a aquellas que por su reconocida honorabilidad y buen sentido, sean una garantía para dar una acertada e imparcial resolución". Véase Decreto No. 410 del Congreso Nacional de la República de Nicaragua, publicado en La Gaceta, Diario Oficial, No. 81 del 15 de abril de 1959.

34 Art. 294 CPP.

35 Bajo este sistema en Octubre del 2004, según los medios informativos nacionales El Nuevo Diario y La Prensa, se realizó el jurado de Byron Jerez Solís, siendo escogido directamente por el Juez Primero de Distrito del Crimen el juez de derecho que integraría el Tribunal, recayendo la designación en el Juez Séptimo Local del Crimen, el cual suspendió sus vacaciones para integrar dicho tribunal de conciencia. Dicho jurado declaró inocente a Jerez, habiendo críticas de diferentes instituciones del Estado por la decisión. Al respecto, la magistrada de la Corte Suprema de Justicia, doctora Yadira Centeno González, comentó que si el jurado de conciencia hubiese estado bajo el nuevo sistema de justicia dominado por el Código Procesal Penal, los resultados habrían sido otros, porque así hay más transparencia.

36 En ese aspecto, la doctora Alba Luz Ramos, magistrada de la Corte Suprema de Justicia, manifestaba: Es cierto que también lo integra un juez, pero éste actúa dentro de ese tribunal como un ciudadano más. Si acaso puede -en forma extraoficial y oficiosa-dar algunos asesoramientos de tipo técnico al resto de los miembros del jurado, pero su papel es el de un jurado más dentro de la integración del tribunal. Véase entrevista brindada a Carmen Herrera, en ocasión de la desinsaculación de los jurados de conciencia en Managua, febrero 1996, publicada en JUSTICIA Órgano del Poder Judicial, pág. 14.

37 Art. 319 CPP.

38 Art. 301 CPP. 
Recuista de Perecho

Como se desprende de lo anterior, el sistema de jurados en materia penal, forma parte de la cultura jurídica nicaragüense a través de su historia. Analizando seguidamente las fortalezas y debilidades del jurado.

\section{Fortalezas y Debilidades}

\section{1. Fortalezas}

Sin duda alguna, y así sostenido, que el jurado es un instrumento de defensa de la libertad y la democracia. Nació como medio de frenar el absolutismo real en los juicios penales y fue adoptado como una consecuencia del sistema democrático en casi todas las legislaciones dictadas desde mediados del siglo XIX hasta principios del siglo XX.

El juicio por jurados ha significado la ruptura del orden jurídico de la Colonia y de la Inquisición, como también la ruptura con la justicia de la burocracia, del expediente, del secreto, del ritual, de la demora sin fin, del lenguaje curialesco incomprensible para el pueblo.

Considerase que la mayor garantía que para los derechos individuales representa el jurado, arranca de su mayor independencia frente a los otros poderes, especialmente al EJECUTIVO.

IHERING, adversario del jurado, reconoce que el juez de carrera -hoy técnico- no puede ser de una manera absoluta, independiente del poder político y señala: "Pero hay una forma de tribunal que realiza esta independencia del más completo modo: es el jurado" 39 .

Es una de las más grandes conquistas de la civilización moderna y una de las más firmes garantías sobre la cual reposan las libertades públicas y privadas. Y en nuestro país ha permitido crear un vínculo entre los diversos sectores de la sociedad civil con la función jurisdiccional, garantizando la participación ciudadana.

Su implementación en el sistema de justicia penal nicaragüense da cumplimiento al principio de rango constitucional que prescribe el derecho de todo procesado en igualdad de condiciones a ser sometido a juicio por jurado en los casos previstos por la ley.

39 Aguilar, Marvin. “Breve reseña de historia...”Op. cit., pág. 122. 
Las personas elegidas como miembros de jurados, tendrán la responsabilidad de emitir fallos, conforme su intima convicción ${ }^{40}$, con el propósito de evitar que los fallos emitidos sean influenciables por los demás miembros que integran el tribunal, y una vez emitido el veredicto proporcionar al procesado la posibilidad de reducir periodos de prisión y definir el estatus legal del mismo ${ }^{41}$.

El veredicto de un jurado es más fácilmente admitido por la ciudadanía que la resolución de un juez y esta institución popular proporcionan a los ciudadanos una oportunidad de participar en la administración de justicia. Al estar constituido por jueces de hecho o legos en derecho, el jurado no realiza la función de juzgar en toda su extensión, sino que solo tiene potestad para decidir si el acusado es responsable o no de la conducta que se le atribuye, en función de los hechos que previamente haya declarado probado, para lo cual debe ser congruente.

La participación ciudadana, a través de esta institución, en la justicia penal es observada como parte del marco constitucional de principios que orientan una visión democrática del proceso penal. Vincula a la ciudadanía en asuntos criminales, sobre todo cuando los mismos ciudadanos son testigos de las dificultades de la investigación, de los obstáculos procesales para el debate de las cuestiones importantes para decidir un asunto, y de los enormes compromisos implícitos en la declaratoria de inocencia o de culpabilidad de una persona. En esta institución, a diferencia del sufragio y de otras formas de participación

40 Señala, el doctor Manuel Aráuz Ulloa, en su artículo "El Tribunal de Jurado en el nuevo Código Procesal Penal", "Que en el proceso penal inquisitivo el jurado, basado en su íntima convicción, puede emitir su veredicto basándose en las pruebas, apartándose de las mismas y aún en contra de ellas, en el proceso penal acusatorio los miembros del tribunal han de emitir su veredicto de acuerdo con lo que, según su criterio lógico y racional, ha quedado probado en la celebración del juicio oral". Véase El Jurado en Nicaragua: Una valoración crítica desde la perspectiva del Derecho Comparado. Managua: Imprenta UCA, 2002, pág. 211.

41 Con alguna rapidez hojeaba la obra de John Grisham, "El Jurado", pág. 620, llamándome la atención, en una de las páginas finales, lo escrito por él sobre el veredicto del jurado, en un caso determinado en los Estados Unidos de América; en el cual reseña: "Acaban de informarme de que el jurado ha emitido un veredicto -anunció Su Señoría hablando a través del micrófono. Desde el estrado veía temblar a los abogados-. Háganlo pasar, por favor. Los doce jurados entraron en la sala en fila india y con expresión solemne, algo común a todos los juicios. Lleven buenas o malas noticias para una u otra parte, estén o no unidos, los jurados siempre mantienen la mirada baja. Eso hace que las dos partes se desanimen y empiecen instintivamente a pensar en la apelación". Esta reseña del autor me ha motivado a escudriñar si la actitud de los jurados "después de haber emitido el veredicto e ingresar con expresión solemne al recinto, con buenas o malas noticias para una u otra parte, siempre mantienen la mirada baja", ha sido de fortaleza para ellos mismos o de debilidad ante las partes del proceso.

Qué encierra en si esta actitud de los jurados al mantener siempre la mirada baja, a fin de que las dos partes se desanimen e inicien a pensar en el recurso de apelación? Porqué no mantener siempre la misma mirada con la cual ingresaron solemnemente al recinto con el veredicto emitido? Quizás una mirada erecta pueda delatarle a una de las partes cuál fue el veredicto? En mi punto de vista la mirada baja denota debilidad frente a cualquier escenario público ante la decisión tomada y la mirada erguida es sinónimo de fortaleza para enfrentar cualquier acción en contrario por parte de quién o quiénes se consideren afectados por la decisión tomada. 
civil, se entiende que participan todos los ciudadanos, incluso los sectores que suelen abstenerse de emitir opinión en otras actividades publicas.

Lainstitucionalidad del jurado es una delas fortalezas dela administración de justicia ${ }^{42}$ y de la sociedad, ya que éste forma una parte importante del sistema legal. Cada vez más se está fortaleciendo una mentalidad juradista por parte de la ciudadanía, que asume al jurado como una institución propia. Su eliminación, como propugnan algunos sectores, sería un severo golpe a la historia y a la misma sociedad, ya que ésta, a través del jurado, pide cuenta de sus actos al acusado o los acusados.

\subsection{Debilidades}

Antaño se esgrimía el aventurado método de selección y la exclusión de él, de la mayoría de las clases profesionales; la inexperiencia en examinar la prueba y su falta de familiaridad con el trabajo de los tribunales; lo prolongado del juicio que conllevaba a un esfuerzo físico y mental de sus miembros; el ser fácilmente influenciado más que un juez técnico por la elocuencia del Abogado.

Hoy se señala que uno de los problemas que presenta esta institución del jurado, es la dificultad para separar las decisiones sobre un caso tomando en cuenta el sistema de valoración de la prueba denominado de intima convicción, de los criterios prejuiciados a partir de bases etarias, ideológicas, de posición social, de credo político o religioso.

Es preciso anotar que la ausencia de un manual o guía de instrucciones del jurado impide que los jueces orienten de la misma forma a los jurados por delitos de la misma especie y eso crea inseguridad jurídica.

Además, muchas de las causas sometidas a su conocimiento presentan complejidad, ya que son de su conocimiento aquellos delitos que ameritan penas más que correccionales, siendo de difícil comprensión el análisis del expediente para sus miembros, que en algunos casos tienen nivel de preparación académico medio, siendo fácilmente influenciados por diversos factores: temor a represalias de los acusados, aspectos económicos.

42 En Argentina la postergación de la institucionalidad del jurado ha sido la principal fuente de la crisis sin retorno del Poder Judicial. 
Se esgrimen cuestionamientos a esta institución del jurado que tienden a debilitarla ante los actores del sistema de justicia ${ }^{43}$ como de la misma sociedad civil, señalándose, además, la poca atención que prestan, ya que toda la prueba es evacuada con testifícales, documentales u otras, que requieren concentración; la contaminación de éste que siempre esta latente; la asignación de mayores recursos económicos para los gastos de alimentación y demás necesidades de los miembros del tribunal, en especial en aquellos juicios que duren varios días y en los que deba mantenerse alejado al jurado de cualquier influencia externa; procurar que por razones económicas no se suspendan los jurados, como ha ocurrido, al igual que se realicen sin la dieta establecida a los mismos; separación de situaciones administrativas con la preselección y selección eminentemente jurídica para su integración; las presiones que pudieren sufrir al aparecer en medios informativos durante la vista y que al momento de emitir su veredicto acerca de la inocencia o culpabilidad de un acusado, voten contaminadamente cuando los hechos pudieren involucrar a la delincuencia organizada.

\section{Jurados interactivos $y$ escabinos, sus viabilidades en Nicaragua}

A medida que el derecho ha venido evolucionando, es necesaria la implementación de reformas en su sistema para adecuarlas a las transformaciones que el sistema de justicia y la sociedad demandan. Si bien, en otras sociedades se mantienen inalterables desde su nacimiento, en otras han sufrido transformaciones.

Referente al establecimiento de un jurado interactivo, cito lo del sistema americano, tal como funcionan ahora, "los juicios con jurado demuestran poca capacidad para la autocorrección y la evitación de exabruptos emocionales. Existen evidencias de que los jurados a menudo son víctimas de su propia lógica, señalando algunos ejemplos: "El jurado del caso Rosenbaum asumió que el policía que solicitó la recompensa departamental estaba probablemente mintiendo; el jurado del caso Kaen asumió que a menos que hubiese un testigo visual del disparo, no habría prueba más allá de una duda razonable; y, el jurado Gotees desarrolló y aplicó una concepción del dolo que la Corte de Apelación de New York ya

43 Así también se han escuchado voces de protesta de las personas que participan como miembro del jurado, en contra de los jueces, al señalar la impuntualidad de éstos durante los juicios a realizarse, el menosprecio a su investidura y el retraso excesivo de la entrega de la dieta que perciben. 


\section{Revisla de Derecho}

había descartado". Las historias de este tipo, alude el autor, son muchas. Sin embargo, hay escasa reflexión sobre cómo mejorar una institución tan arraigada en la concepción americana de la justicia.

La interacción entre el jurado y el juez capacitaría al jurado para comprender mejor las instrucciones sobre el derecho. Los jueces deberían ser menos formalistas a la hora de dar las instrucciones, deberían incitar al jurado a formular preguntas mientras las situaciones se van sucediendo y las opciones legales se van acumulando. Los jueces podrían señalar los elementos que son particularmente interesantes, invitando a los miembros del jurado a formular preguntas; preguntarles a sus miembros si habían entendido o no toda esta jerga legalista". Finalmente, aluden, estas formas sencillas de comunicación es lo que uno espera de un procedimiento, y citando a Tocqueville: "es la manera más eficaz de educar al pueblo que la sociedad puede emplear”44.

En este proceso se hace referencia a tres sistemas clásicos del modelo de jurado que han incidido en esta institución y que se aplican en diferentes países. Siendo los modelos: puro, mixto y escabino.

\subsection{Modelo Puro}

Esta institución en la cual el pueblo interviene en la administración de justicia en materia penal, antaño integrado por un conjunto de 12 personas que deciden la culpabilidad o inocencia del acusado sin fundamentar su decisión, es lo que se denominó Jurado Puro. En 1791, Francia adoptó el modelo inglés, pero las grandes y graves dificultades aparecidas en la práctica para distinguir el hecho del derecho motivaron una evolución, que culminó en 1941, hacia el Escabinato. España y sus colonias en el Nuevo Mundo implementaron, y aún predominan, el modelo puro.

EstemismomodeloestrasladadoalasColoniasBritánicasenNorteamérica, el cual está garantizado por la VI Enmienda a la Constitución de los Estados Unidos de 1787. El elemento más característico del sistema por enjuiciamiento por jurado vigente en esa nación, tanto en la Unión como en cada uno de los Estados, es la vigencia del gran jurado, cuya Enmienda establece: "Ninguna persona podrá ser acusada por un crimen infamante salvo por presentación o inculpación de un Gran Jurado”. Tribunal éste

44 FLETCHER, George P. "Las Víctimas ante el Jurado". Valencia: Edita: Tirant Lo Blanch, C/ Artes Gráficas; 1997, págs. $338-339$. 
integrado entre 16 y 23 ciudadanos seleccionados al azar, a partir de las listas del registro de votantes, convocados para determinar si existe causa probable para creer que una persona ha cometido el delito federal del cual ha sido acusada, y tomar decisiones por mayoría de votos. En caso resultar positiva, el portavoz presenta un acta de inculpación, que constituye la base de la posterior acusación que se formaliza ante un Jurado integrado por 12 personas que habrán de decidir sobre la inocencia o culpabilidad del $\mathrm{reo}^{45}$.

Inglaterra lo adopta a partir de la invasión de Bretaña en 1066. A mediados del siglo XII, se posibilitó solicitar el derecho a tener un jurado que decidiese sobre un caso. Estaba compuesto por hombres de la vecindad en la que habían tenido lugar los hechos, seleccionando a aquellos que tenían mas información sobre lo sucedido. Cuando una de las partes en litigio conseguía que 12 de los jurados se manifestasen a favor de su tesis, ganaba el caso. Este es el origen del jurado tradicional compuesto por 12 miembros y que decidía por unanimidad ${ }^{46}$.

Juan Luís de la Rúa, al referirse al modelo puro que rigió en España, señala que "En esta configuración, ciertamente compleja, pues se quiera o no la construcción razonada tanto de la culpabilidad como de la no culpabilidad presupone adentrarse en el mundo de los conocimientos jurídicos por parte de quienes carecen de ellos, han de encontrarse las múltiples y continuadas críticas de la mayor parte de los sectores doctrinales, así como de instituciones tan significativas como el Consejo General del Poder Judicial y la Fiscalía General del Estado”47.

Otro autor, como el profesor Víctor Fairen Guillén, destaca: "La imposibilidad de que los miembros del jurado lleguen a obtener la preparación suficiente para resolver con las simples instrucciones que les pueda impartir el Magistrado-Presidente, por muy bien que éste lo haga, ha calificado el Jurado como el "Pentecostés laico"48.

45 Semblanza del Sistema Jurídico de EE.UU.

46 A partir de 1967, se admitió la adopción de un veredicto por mayoría de 11 sobre 12 miembros, o de 10 votos sobre 11 miembros, siempre que después de las dos primeras horas de votación no se hubiere alcanzado unanimidad.

47 DE LA RÚA, Juan Luís. "Consideraciones Generales acerca del Tribunal de Jurado a la luz de la Legislación Española”. El Jurado en Nicaragua: Una Valoración Crítica desde la Perspectiva del Derecho Comparado. Managua: Imprenta UCA, 2002, pág. 10.

48 DE LA RÚA, Juan Luís. “Consideraciones Generales acerca...” Op. cit., págs. 10-11. 


\subsection{Modelo Mixto}

Coexisten al mismo tiempo el Tribunal del Jurado y el Tribunal de Escabinos ${ }^{49}$.

El Tribunal del Jurado está compuesto por tres jueces profesionales, siendo uno de ellos el Presidente, y ocho jurados legos. En cambio, el Tribunal de Escabinos esta formado por dos jueces profesionales, uno de los cuales es el Presidente, y dos ciudadanos. En el primero, su competencia se ciñe a los delitos más graves y políticos; y el otro, a infracciones de menor importancia.

Los miembros legos del Tribunal de Jurado pronuncian, además del veredicto, en caso sea de culpabilidad, la resolución de las cuestiones relativas a la imposición y aplicación de la pena correspondiente. Siendo ésta competencia del Tribunal del Jurado, considerado como un todo al modo del Escabinado. En cambio, la resolución de las demás cuestiones técnicas es competencia exclusiva de los jueces profesionales, quienes tienen la posibilidad de revisar la corrección del veredicto y la penalidad impuesta.

\subsection{Modelo Escabino}

Francia instituye el jurado en 1791, a raíz de su Revolución. Concebido a semejanza del modelo inglés, cual era el modelo puro. En 1941 culmina el proceso de evolución legislativa, cerrando una etapa, y dando inicio, en virtud de una auténtica ruptura con su tradición, a una nueva etapa, que supuso la supresión del jurado como modelo puro instaurándose explícitamente los Tribunales de Escabinos, conformados con seis legos y tres jueces profesionales, que participan conjuntamente en la determinación de los hechos probados y en la aplicación de la ley penal, rigiéndose por un criterio mayoritario en la adopción de decisiones. Actualmente está integrado por tres magistrados profesionales, uno de los cuales actúa como Presidente, y nueve legos.

En su origen, el jurado francés tenía la misión de conocer exclusivamente las cuestiones de hecho, reservándose, con exclusiva separación de

49 En la legislación procesal penal venezolana, según su artículo 146, "Todo ciudadano tiene el derecho a participar como escabino o jurado, en el ejercicio de la administración de la justicia penal. Cuando el ciudadano concurra a integrar un tribunal mixto se le denominará escabino, y cuando forme parte de un tribunal de jurados se le denominará jurado; sin que, en ambos casos, sea abogado". 


\section{Revisla de Perecho}

funciones, a los Magistrados, la resolución de los problemas derivados de la aplicación del Derecho. Pero este sistema pronto se reveló como peligroso. "Los jueces de hecho, posiblemente con el ánimo condicionado por el temor de que ante un veredicto de culpabilidad, los jueces de derecho aplicaran una pena que estimaran excesivamente rigurosa, optaron en muchas ocasiones por anticiparse a tal evento, pronunciando veredictos de total INCULPABILIDAD".

Se intentó corregir esta situación en 1832, que otorgó al Jurado la facultad de conocer de las atenuantes de la responsabilidad penal. "Sin embargo, y por cuanto que mediante su apreciación, las facultades de los jurados aparecían limitadas a, en cualquier caso, rebajar la pena en un grado, su ánimo continuaba siendo sensible a la apreciación de una excesiva rigurosidad en el proceder de los Magistrados profesionales, lo que continuó llevando al masivo pronunciamiento de veredictos de absolución".

En la legislación de 1932, se estableció que, "con independencia del juicio de hecho, jurados y magistrados habían de votar conjuntamente la concreción de la pena”. Así esta reforma aproximaba el jurado francés al Escabinado ${ }^{50}$.

Hasta la Ley de 1978, los jurados eran elegidos por el GobernadorPrefecto, entre los buenos ciudadanos durante la II República. Al entrar en vigencia esta Ley, los ciudadanos llamados a integrar el jurado son elegidos mediante un sorteo basado en la lista electoral de cada Departamento ${ }^{51}$.

Sucompetenciamaterialseextiende, con caráctergeneral, al conocimiento de los crímenes, siempre que no hayan sido cometidos por menores de dieciséis años, quedando excluidos de su conocimiento, salvo los casos de conexidad delictiva, los delitos menos graves y las contravenciones o faltas. La sentencia condenatoria requiere el voto de ocho miembros, y en cuanto a la imposición de la pena, se requiere el voto favorable de la mayoría absoluta de los miembros, exigiéndose ocho votos si se fija en su grado máximo ${ }^{52}$.

50 VILATA MENADES, Salvador. "Sobre el Jurado: Un Análisis desde una Perspectiva Distinta". Valencia: Editorial Práctica de Derecho, S.L.; 2001, pág. 177.

51 VILATA MENADES, Salvador. "Sobre el Jurado...”" Op. cit., pág. 178.

52 VILATA MENADES, Salvador. "Sobre el Jurado...” Op.cit., págs. 178-179. 


\subsection{La viabilidad del Jurado escabino en Nicaragua}

Surge actualmente una corriente evolutiva, tendiente a implementar el modelo escabino, adoptado por la corriente francesa. Recordemos que Francia adopta de Inglaterra el modelo puro y posteriormente, a partir de 1810, inicia su revolución al modelo escabino y el cual ha pasado a Alemania e Italia y es el predominante en Europa continental. En España hay voces pidiendo una reforma con tendencia hacia el escabinado. Nicaragua ha planteado la posibilidad de poner a impartir justicia a un jurado escabino.

Si bien en la Carta Magna de Cádiz, como resaltaba, se instituyó un modelo por su conformación similar al modelo escabino, sin conocerse cuántos jueces de hecho y cuántos jueces de derecho lo integraban. Las Leyes reformatorias sobre el Tribunal de Jurados de 1979 y 1993, respectivamente, incorporan al juez de derecho, además de los jueces legos, es decir, otra similitud del escabinado, pero sin el procedimiento establecido para esta clase de jurados ${ }^{53}$.

Por los actuales cuestionamientos al sistema de justicia de diversas índoles, la polarización de la sociedad, la carencia de recursos económicos suficientes para esta transformación en los aspectos humanos, estructurales y materiales, como la tendencia de una corriente que propugna por la supresión del jurado, hace inviable esta reforma. No descartándose que superadas las causas predominantes actualmente hagan viable el establecer un tribunal de jurado escabinado en Nicaragua.

Antes de llegar a este modelo, se producirán reformas a la actual codificación penal, que establece que todo acusado por la presunta comisión de un delito grave tiene derecho a ser juzgado por un jurado, excepto los relacionados con las drogas o con el lavado de dinero y activos provenientes de actividades ilícitas. Quizás permanecerán algunos delitos que serán del conocimiento del jurado, pero en los que no lo sean, tal como está establecido, corresponderá al juez de derecho la

53 En el dictamen emitido por la Comisión de Justicia de la Asamblea Nacional de Nicaragua, el 2 de marzo de 1990, sobre el Proyecto de Ley de Reforma Procesal Penal, para modificar el Decreto No. 1130, publicado en La Gaceta, Diario Oficial del 10 de noviembre de 1982, en uno de sus párrafos, señalaba: “Con estos propósitos se recomienda que el Tribunal de Jurado esté integrado por un número de ciudadanos acorde con la población de los distritos judiciales compuesto por jueces de derecho, especialistas por razón del oficio y jueces ocasionales que aprecien los hechos y la culpabilidad del acusado, conforme al dictamen de la conciencia”. 
responsabilidad de resolver acerca de la culpabilidad o no culpabilidad del acusado, así como sobre la pena que corresponda ${ }^{54}$.

\section{Reformas al Sistema del Jurado}

Han surgido voces, al igual que propuestas interinstitucionales ${ }^{55}$, reconociendo la importancia que ha tenido la institución del jurado en la vida jurídica nacional y recomendando reformas al sistema de jurados en Nicaragua, en el cual éste se establezca para todos los delitos, dejando a salvo un grupo que afecta intereses sensibles para el sistema de justicia penal, como son los de mayor incidencia, tales como delitos sexuales, violencia intrafamiliar, hurto, robo, lesiones, lavado de dinero, abigeato y drogas, los que deberán ser juzgados siempre por un juez técnico.

En mi criterio, además de la exclusión de los actuales ilícitos y los que se impulsan promover, debería ser reformado lo atingente a la sentencia absolutoria dictada por el juez ${ }^{56}$, si en el segundo juicio, vencido el plazo tampoco se lograra veredicto por el jurado. No debe haber vencimiento, sino repetir el juicio cuantas veces sea necesario hasta que el jurado alcance una decisión, ya sea ésta de culpabilidad o de no culpabilidad.

De lo dicho puede apreciarse que se trata de una previsión criticable para la que no se encuentra justificación, considerándose como que el legislador se rinde ante un fracaso decisorio y optó por una fórmula manifiestamente inaceptable.

Debiendo ser congruente con lo consagrado en el Art. 319, párrafo cuarto CPP, que señala: "Cuando a instancia del......, el jurado considere suficientemente debatido...., se procederá a votar en forma secreta,........., pronunciándose la culpabilidad o no culpabilidad....... Si son varios los cargos,..... Este procedimiento se repetirá cuantas veces sea necesario hasta obtener el veredicto".

Igualmente sobre la votación, si bien actualmente se requieren cuatro votos en un solo sentido para que haya veredicto, debe modificarse en

54 Art. 293 CPP.

55 Como la acordada por la Comisión Nacional de Coordinación Interinstitucional del Sistema de Justicia Penal, en su reunión de abril 2007.

56 En este sentido, Pérez CEBADERA, MARIA-ANGELES, “Las instrucciones al Jurado”, cit., pág. 420-421, señala que "El Magistrado-Presidente habrá de dictar una sentencia absolutoria que, por su contenido, puede calificarse como una sentencia meramente procesal, esto es, una resolución sin juicio histórico y que, por consiguiente, dejará imprejuzgado el hecho principal que conformaba el objeto del proceso"; sustentado en el Informe acerca de la experiencia aplicativa del Jurado de la Fiscalía General del Estado Español. 
cuánto al número de votos requeridos para la culpabilidad y en cuánto para la no culpabilidad. Debiendo ser mayor para el primero y menor, para el segundo.

Además, aumentar el número de miembros titulares que integrarán el Tribunal de Jurado, para la viabilidad y aplicación del número determinado de éstos para que haya veredicto en uno u otro sentido.

Así también, podría establecerse que los candidatos a jurados llenen cuestionarios para determinar si son idóneos para prestar servicio en un jurado. Posteriormente, se revisan los cuestionarios y se escoge al azar a aquellos que serán citados para que presten el servicio.

Quizás por el momento estas propuestas no sean factibles, dado su reciente nacimiento, pero con el devenir del tiempo si lo serán, éstas y otras. Lo único que no podrá ocurrir es la supresión del jurado, aún con sus cuestionamientos. Nicaragua no tuvo grata experiencia cuando se abolió a finales de los años 8o, fundamentando con sutileza los abolicionistas, en: la lentitud en la celebración de los juicios y la falta del principio de inmediación, que llegó a constituir una institución disfuncional; el elevado porcentaje de absoluciones, que le brindaban la libertad a personas que constituían un verdadero peligro para la sociedad y condenaban a otras que podrían haberse adaptado nuevamente y ser útiles a la misma; que era incompetente y nulo, lo cual, estaba acarreando grandes perjuicios a la administración de justicia y no daba respuesta. Concretando los propulsores que los defectos y fallas del jurado no es por culpa de los integrantes, sino de las condiciones en que se procedía. Pero el fondo de la abolición era por ser crítico del sistema político de ese entonces (1979-1990). Sustentándose en leyes emitidas desde el triunfo de la revolución popular sandinista, las cuales, aludían, se encuentran nutridas de los principios rectores del FSLN ${ }^{57}$, que tienen como objetivo la participación directa del pueblo en el Estado. Surgiendo el problema, indicaban, cuando no existe una norma revolucionaria, nacida a partir del 19 de julio de 1979, que regule la posible aplicación a un caso concreto y sea necesario acudir a las leyes pre-revolucionarias o sea, a los códigos tradicionales. Aquí es donde el juzgador deberá hacer uso de

57 Frente Sandinista de Liberación Nacional, partido político de izquierda. Surgió inicialmente como movimiento guerrillero, el cual asumió el poder político de Nicaragua con el triunfo de la Revolución Popular Sandinista el 19 de julio de 1979; institucionalizándose en partido político, conforme el Art. 36 de la Ley de Partidos Políticos, Decreto No. 1312, publicado en La Gaceta No.210, del 13 de septiembre de 1983. 
Revista de Derecho

toda sabiduría de tal modo que, la interpretación que le dé a la norma pre-revolucionaria, esté de acuerdo con los principios y postulados de esa revolución ${ }^{58}$.

Con dichos argumentos se establecieron a finales de 1979, los Tribunales Especiales de Primera Instancia y de Apelación ${ }^{59}$, para conocer de los delitos tipificados en el Código Penal, cometidos por militares, funcionarios y empelados civiles del régimen somocista y cualquier otra persona que amparada por sus relaciones con ellos, hubiera participado en la comisión de los mismos. Según el decreto creador de estos Tribunales, una vez concluido el término probatorio y no habiendo nulidades, éste en sesión secreta y por mayoría de votos, sin más trámite dictaba resolución de conciencia, acerca de la calificación del delito y de la inocencia y culpabilidad del procesado.

Estos Tribunales fueron disueltos en 1981, dejando secuelas dolorosas en la comunidad nicaragüense, ya que no había seguridad jurídica y protección de los derechos humanos para quienes eran juzgados, y a través de dichos tribunales se condenó a muchos sin estar comprendidos dentro de la calificación, contemplada en el Decreto No. 34/197960, aplicando el juzgador la norma en base a los principios y postulados de la revolución.

En 1988, al suprimirse el jurado por ley, se estableció que correspondía a la Procuraduría General de Justicia el ejercicio exclusivo de la acción penal y que los juicios criminales se iniciaban por acusación o denuncia por parte de ésta, en los delitos en que existía la exclusividad de la acción penal ${ }^{61}$; y de la Policía Sandinista a través de la remisión del expediente.

58 Expresaba el doctor Roberto Lemus, en su ponencia "EL JUEZ ANTE LA CONCURRENCIA DE LAS LEYES REVOLUCIONARIAS CON LOS CODIGOS TRADICIONALES”, en el Seminario Jurídico "LA JUSTICIA EN LA REVOLUCION", auspiciado por la Corte Suprema de Justicia, realizado en Managua, del 19 al 23 de mayo de 1981, al referirse a la norma revolucionaria y a las leyes pre-revolucionarias, que: "Las normas, tanto fundamentales como ordinarias nacidas a partir del 19 de julio de 1979, responden a los intereses populares, ya que el poder político en este país lo tiene el conjunto de fuerzas populares y democráticas". Y "las leyes prerevolucionarias (Códigos Tradicionales) en su significado literal no responden, en general, a los intereses del pueblo,..."

59 Decreto No. 185, Ley Creadora de los Tribunales Especiales, del 29 de noviembre de 1979, publicado en La Gaceta No. 75, del 5 de diciembre de ese mismo año.

60 Ley Creadora de los Tribunales Especiales de Emergencia del 7 de agosto de 1979, publicada en La Gaceta No. 4, del 28 de agosto de 1979.

61 En el dictamen de la Comisión de Justicia del parlamento nicaragüense, sobre el proyecto de reforma a la Ley de Reforma Procesal Penal, Ley No. 37 del 13 abril 1988, con fecha 19 diciembre 1990, tendiente al restablecimiento del juicio por jurado, esta Comisión, al referirse al ejercicio de la acción penal, expresaba: “....., y a la vez reconociendo el derecho ciudadano de que los agraviados puedan ejercer dicha acción; es decir, se termina con el monopolio de la acción penal en manos del Estado. Esto lo consideramos absolutamente necesario para dejar a un lado el retroceso en materia penal". 
De acuerdo a la Ley de Reforma Procesal Penal de ese año, se instituyó que los jueces y tribunales valorarían los medios probatorios de conformidad con las reglas de la sana crítica y que en consecuencia en Nicaragua no se aplicarían los sistemas de valoración probatorios conocidos en las legislaciones de derecho comparado con los nombres de prueba legal o tasada, prueba libre o sistema de íntima convicción. Derogándose toda disposición que se refería a la plena prueba, semiplena prueba y otros términos análogos de prueba tasada ${ }^{62}$.

\section{La justicia impartida por el pueblo, a través del Jurado. Obligaciones y Responsabilidades. Inclusión o Exclusión en el sistema de jurados de determinados ilícitos penales}

\section{La justicia impartida por el pueblo a través del Jurado}

El Tribunal de Jurados, como reseñaba, tiene una larga tradición en la historia de la humanidad, es la forma más directa que la población ha tenido para participar en la toma de decisiones para ejercer la justicia y la alta conciencia cívica de un pueblo se debe a la participación de éste en los jurados que periódicamente los pone frente a la responsabilidad de juzgar.

Sin embargo, a comienzos del pasado siglo, refería José Canalejas Rubio, varias veces se ha intentado abolir el jurado; pero sin lograrlo, porque no se ha encontrado un algo que reúna más ventajas. Indicando, entre ese algo, dotar a unos jueces inteligentes e imparciales de sueldos que les dé independencia; castigar sus culpas severísimamente; escoger esos hombres, entre otros varios, de una manera justa e imparcial, no por medio de oposiciones en que se les designa antes de su examen; oír los informes de peritos, sobre todo de médicos, y el jurado podrá desaparecer. Cómo explicarse que ha podido vivir tantos años, una institución sensiblera ${ }^{63}$ e ignorante, que a sabiendas juzgan mal los delincuentes para su absolución y agradecimiento ${ }^{64}$.

62 Cuarezma Terán, Sergio J. “Código de Instrucción Criminal. Comentado, concordado y actualizado”. Managua: Editorial HISPAMER, 1997, pág. 209.

63 Es criterio general que porque los jurados son gente sensible y falaz, condenan a menos criminales a la pena de muerte, lo que no es verdad. Mr. Holtzendorff demostró que los magistrados son más sensibles que los jurados. Véase Rubio Canalejas, José. La Pena de Muerte. Biblioteca de la Facultad de Derecho de la Universidad de Sevilla. Edición digital jabyn@us.es, págs. 37/38.

64 Canalejas Rubio, José. “La Pena...” Op. cit., pág. 37. 
Revista de Q)erecho

\title{
Dentro de las formas históricas de lajusticia angloamericana en el proceso de implementación de la estructura de poder paritaria, destacaban: el jurado autoinformado; los jueces de paz; y el gran jurado ${ }^{65}$.
}

\author{
Anterior a las reformas constitucionales de 1995 y restablecido el Tribunal \\ de Jurados por la Ley No. 164 de 1991, vigente en febrero de 1992, se \\ consagraba que esta Institución es una forma de participación popular ${ }^{66}$ \\ en la administración de justicia ${ }^{67}$; es un sistema de administración de
}

65 Los miembros del jurado autoinformado eran convocados por los jueces reales para expresar la voz rural, permitiéndoseles llevar a cabo su propio trabajo detectivesco. En parte, la operación de este sistema de jurado consistía en investigaciones informales llevadas a cabo por funcionarios legos temporales; siendo esto un caso claro de la forma paritaria activista. Los jueces de paz tenían una gran autoridad en la aplicación del derecho penal, con poderes para llevar a cabo individualmente investigaciones de delitos graves y, compuestos en paneles, podían juzgar delitos menores. Sus decisiones eludían el control de la autoridad central y su actividad era poco regulada y bastante informal; las huellas de sus acciones no se guardaban en archivos. Los procesos ante ellos revelaban características de un estilo inquisitivo paritario. El gran jurado, como funcionara durante ciertos períodos de su historia, proporciona otra ilustración de la forma inquisitiva adaptada a la participación de funcionarios legos ad hoc. No había un fiscal público que actuara ante los jurados, de modo que sus procesos han de imaginarse como investigaciones amateurs informales. La acción del gran jurado no se basaba necesariamente en las quejas contra una persona designada, ni siquiera eran dirigidas a un delito en particular. Eran posibles las investigaciones amplias sobre temas que afectaban a la comunidad, más amplias que la inquisitio generalis de los antiguos procesos penales en el continente. Si los procesos del gran jurado resultaban en una acusación y el acusado se declaraba culpable, las sentencias se dictaban sobre la base de investigaciones informales por amateurs locales. Pero las acusaciones podían ser acompañadas por informes dirigidos a problemas más amplios que el caso particular de conducta penal ante el jurado. Véase Damaska, MR. Las caras de la justicia y el poder del Estado. Santiago-Chile: Editorial Jurídica de Chile, 2000; págs. 388, 392 y 393.

66 Al amparo del Estado de Emergencia Nacional, de las normas del Pacto Internacional de Derechos Civiles y Políticos y del Estatuto sobre Derechos y Garantías de los Nicaragüenses, aludiendo una situación de excepción que requiere de órganos judiciales ágiles, que con carácter temporal, mientras dure el Estado de Emergencia, en 1983, la entonces Junta de Gobierno de Reconstrucción Nacional, creó los Tribunales Populares Antisomocistas de Primera y Segunda Instancia, para juzgar y castigar los responsables de los crímenes de guerra o crímenes de lesa humanidad, contemplados en los Artículos 1 y 2 del Decreto No. 1074 del 6 de junio de 1982 y los conexos con estos tipificados en el Código Penal. Terminología sumamente peyorativa, ya que estos tribunales no representaban la participación popular en la administración de justicia ni juzgaban según su criterio lógico y racional, sino que eran tribunales de excepción, eminentemente político-partidistas. A pesar que, el 10 de enero de 1987, con la promulgación y publicación en La Gaceta de la Constitución Política, se estableció un nuevo orden institucional, en la cual se garantizó que, entre otras, todo procesado debe ser juzgado sin dilaciones por tribunal competente; y, que la administración de justicia se organizará y funcionará con participación popular; el Presidente de la República, a través de Decreto Ejecutivo, el 6 de febrero de 1987, estableció los Tribunales Populares Antisomocistas de Primera Instancia en diferentes regiones geográficas del país, así como el de Apelación en Managua. Tribunales éstos que, por la presión nacional e internacional, fueron derogados. Véanse Artículos 34 y 166 Cn., y Decretos Nos. 1233, 249 y 295, del 11 de abril de 1983, 6 de febrero de 1987 y 19 de enero de 1988, publicados en La Gaceta Nos.82, 34 y 13, del 12 de abril de 1983, 12 de febrero de 1987 y 20 de enero de 1988, respectivamente.

67 En las conclusiones sobre participación popular en la administración de justicia, en mayo de 1981, se reseñaba: "1. Que a partir del 19 de julio de 1979, se estableció por voluntad del pueblo, un nuevo Estado Democrático, popular y antiimperialista que expresa la voluntad de una conjunción de fuerzas populares: clase obrera, campesina, de pequeños y medianos productores y de un sector limitado de la burguesía patriótica, así como de otras capas sociales formadas por estudiantes e intelectuales y trabajadores en general. 2. Que un Estado de este tipo requiere la participación popular efectiva en las actividades de la administración, de la economía y de todos los órdenes, incluso las del Poder Judicial. 3. Que los Tribunales de Justicia ordinarios han conservado las mismas estructuras organizativas y funcionales en las que realmente la participación popular, en el sentido estricto de elección y representación de las masas trabajadoras no existe”. La Justicia en la Revolución. Memoria del Seminario Jurídico Silvio Mayorga. Corte Suprema de Justicia. Nicaragua, Mayo 1981, pág. 692.

Sin embargo, el entonces Ministro del Interior, Tomás Borge Martínez, en su exposición sobre la "Ley de Reforma Procesal Penal" ante el Consejo de Estado, el 28 de julio de 1982, expresaba: "El jurado no implica ninguna participación popular, todo eso es falso, este es un argumento que se basa en un sofisma, es en realidad más que 
justicia en materia penal, donde el ciudadano en pleno goce de sus derechos civiles y políticos, conforme los requisitos establecidos en la ley, eran elegidos anualmente para integrar tribunales de justicia y resolver de forma definitiva, causas o delitos con penas más que correccionales; fallando de acuerdo con su conciencia o su íntima convicción. Quedando fuera de estos tribunales de conciencia los delitos que venía conociendo la jurisdicción militar.

Su importancia resaltaba en el hecho que la sociedad nicaragüense, a través del Estado y éste a su vez de la ley, deja en manos de los ciudadanos electos jurados, la potestad de administrar o impartir justicia en las causas o juicios, en que se resuelven los delitos más graves, los cuales tienen las penas de prisión y accesorias más fuertes.

Así, participa activamente la sociedad en los asuntos públicos, especialmente aquellos en que está en discusión y para la sanción la conducta de miembros de la sociedad, que se han visto involucrados en hechos que atentan contra las personas y la sociedad en su conjunto.

La responsabilidad confiada por la sociedad, a ciudadanos de las diversas esferas sociales, es mayúscula, porque se enfrentan con causas en las cuales, conforme su conciencia, resolverán si los procesados son inocentes o culpables del ilícito que se investiga.

Según nuestra Carta Magna, la proclamación del estado nicaragüense como una República democrática, participativa y representativa ${ }^{68}$ y como un Estado Social de Derecho ${ }^{69}$ tiene su continuación en la expresión de que la soberanía nacional reside en el pueblo ${ }^{70}$. Y en lo que al Poder Judicial se refiere, de que la justicia emana del pueblo, se legitima de esta manera, constitucionalmente, la participación de los ciudadanos

todo una ficción, una cortina de humo para obviar la verdadera participación popular en la administración de la justicia. La única posibilidad, o la única respuesta posible para una real participación del pueblo en este sentido, es la instauración de los tribunales populares, donde se conjugue la participación de las organizaciones de masas con elementos entendidos en derecho; esta conjugación dialéctica es la única correcta para obtener una justicia expedita, eficiente y revolucionaria”. MONEXICO Revista del Consejo de Estado, noviembre 1982, pág. 54.

68 Art. $7 \mathrm{Cn}$.

69 "Es aquel que reconoce la titularidad de los grupos sociales, entendidos éstos como sujetos de Derecho, y la conveniencia sociológica de la participación de la sociedad civil en la construcción de la democracia política, económica y social". Y Estado de Derecho es la subordinación de todos, gobernantes y gobernados, al imperio de la Ley. Cit. Serrano Caldera, Alejandro. "Estado de Derecho y Derechos Humanos". Managua: HISPAMER, 2004, págs. 16/22.

70 Art. $130 \mathrm{Cn}$. 


\section{Revisla de Perecho}

en la administración de justicia, lo que es de suma importancia en la democratización de ese poder del Estado ${ }^{71}$.

Afianzándose de esta manera que, el Tribunal de Jurado viene a ser una manifestación del principio democrático que refuerza la legitimación del ejercicio de la función jurisdiccional de los tribunales, ya que los jurados son jueces, y por tanto, ejercen la función jurisdiccional en los casos establecidos en la ley.

$\mathrm{Al}$ respecto, la Constitución Política, establece: "La administración de justicia se organizará y funcionará con participación popular, que será determinada por las leyes. Los miembros de los Tribunales de Justicia, sean abogados o no, tienen iguales facultades en el ejercicio de sus funciones jurisdiccionales" ${ }^{2}$.

El CPP, estatuye que el jurado es la institución mediante la cual el pueblo interviene en la administración de justicia en materia penal; y todo ciudadano que cumpla con los requisitos establecidos en dicho cuerpo de leyes, tiene, en principio, el derecho-deber de participar, como miembro de jurado, en el ejercicio de la administración de la justicia penal ${ }^{73}$.

Consagrándose con las disposiciones de los artículos 12 y 41 CPP, relativas al derecho de todo procesado y al deber de todo ciudadano, que para el procesado el hecho de que su causa sea sometida a un juicio por jurados es un derecho potestativo, para los demás ciudadanos integrar un tribunal de jurados ha quedado establecido como un deber, incluso constitucional, a partir de la reforma constitucional de 1995 al artículo $51^{74}$.

\section{Obligaciones y responsabilidades}

Es oportuno, según mi criterio, una breve introducción sobre las obligaciones y responsabilidades del jurado, a través de una definición de ambos vocablos.

\footnotetext{
71 En España esta establecido, en el artículo 125 de su Constitución Política, que "los ciudadanos podrán ejercer la acción popular y participar en la administración de justicia mediante la institución del jurado, en la forma y con respecto a aquellos procesos penales que la ley determine, así como en los tribunales consuetudinarios y tradicionales".

72 Arto 166.

73 Arto 41 Código Procesal Penal de Nicaragua.

74 Aráuz Ulloa, Manuel. "El tribunal de Jurado......" Op. cit., pág. 212.
} 
Obligación, según Manuel Ossorio, "Deber jurídico normativamente establecido derealizar omitir determinado acto, ya cuyo incumplimiento por parte del obligado es imputada, como consecuencia, de una sanción coactiva"75.

Este mismo autor, al referirse a la Responsabilidad, señala: "Para la Academia, deuda, obligación de reparar y satisfacer, por sí o por otro, a consecuencia de delito, de una culpa o de otra causa legal". En cuanto a la responsabilidad judicial, añade: "La exigible a los miembros del Poder Judicial por infracción culposa o dolosa de sus deberes y funciones" ${ }^{\prime 6}$.

Algunos autores, incurren en el error de confundir obligación con responsabilidad, cuando en realidad se trata de cosas distintas y bien diferenciadas, prevaleciendo doctrinariamente el criterio de que en la obligación se ofrecen dos elementos: la deuda considerada como deber, por una parte; y, la responsabilidad, por otra. Señalándose que la responsabilidad constituye un elemento agregado al solo efecto de garantizar el cumplimiento del deber ${ }^{77}$.

Constitucionalmente, y así consagrado en el Art. 51, párrafo segundo, es deber del ciudadano desempeñar los cargos de jurado, salvo excusa de ley. Bajo ese precepto y conforme lo estipulado en el CPP, una vez que han sido convocados éstos tienen que cumplir con las OBLIGACIONES establecidas. En caso de incumplimiento, una vez debidamente citado, se le sanciona con una multa equivalente al doble de la dieta que habría de percibir por el desempeño de su función y si reincidiere, el juez le impondrá el doble de la multa antes señalada ${ }^{78}$.

Los jurados, reza la disposición legal, tienen las OBLIGACIONES siguientes:

1) Atender a la convocatoria del juez en la fecha y hora indicadas;

2) Informar al tribunal en la audiencia de integración acerca de los impedimentos existentes para el ejercicio de su función;

3) Prestar promesa de ley;

4) Cumplir las instrucciones del juez acerca del ejercicio de sus funciones;

75 Ossorio y Florit, Manuel. "Diccionario de Ciencias...” Op.cit., pág. 659.

76 Ossorio y Florit, Manuel. "Diccionario de Ciencias...” Op.cit., pág. 876-878.

77 Ossorio y Florit, Manuel. "Diccionario de Ciencias...” Op.cit., pág. 876 - 877.

78 Art. 50 CPP. 
5) No dar declaraciones ni hacer comentarios sobre el juicio en el cual participan;

6) Examinar y juzgar con imparcialidad y probidad; y,

7) Las demás establecidas en el presente Código"79.

Además, de las OBLIGACIONES citadas, los jurados deben cumplir con ciertos requisitos para participar como tal. Así también, gozan de los deberes y derechos laborales por el desempeño de la función y la obligación del Estado de pagarle una dieta por dicho desempeño.

Considero que dentro de las OBLIGACIONES, antes enunciadas, de los jurados, a mi criterio dos conllevan mayor grado de RESPONSABILIDAD, siendo éstas: "5.- No dar declaraciones ni hacer comentarios sobre el juicio en el cual participan; y, 6.- Examinar y juzgar con imparcialidad y probidad".

Señala nuestro cuerpo de leyes la RESPONSABILIDAD del jurado, si éste en el momento de la deliberación, la cual es secreta y continua, revelare lo que en ella se ha manifestado, ya que ninguno puede revelar ni comunicarse con persona alguna hasta que se emita el veredicto ${ }^{80}$.

Otra RESPONSABILIDAD, que conllevaría aplicación de pena, es al momento de la decisión, cuando concluida la lectura del veredicto del jurado, el juez ordena a sus miembros retirarse; advirtiéndoles acerca de la OBLIGACION que tienen de abstenerse de comentar aspectos alguno acerca de la deliberación, votación y veredicto ${ }^{81}$.

\section{Inclusión o Exclusión en el sistema de jurados de determinados ilícitos penales}

\section{Breves antecedentes históricos de la Inclusión o Exclusión de ciertos ilícitos al conocimiento del Tribunal de Jurados, a partir de 1981}

En 1981, se estableció que los Tribunales Comunes eran los competentes para conocer de las infracciones a la "Ley sobre el Mantenimiento del Orden y Seguridad Pública”; y que los jueces y tribunales debían admitir y apreciar las pruebas según las reglas de la sana crítica, sin estar

79 Art. 42 CPP.

80 Art. 319, párrafo 2, CPP.

81 Arto 320 CPP. 
sometidos a las reglas de la prueba legal o tasada, ya que estas causas no estaban sometidas a jurados.

La Reforma Procesal Penal de 1982, señalaba en qué casos procedía el jurado; indicándose únicamente cuando éstos sean más que correccional. Siendo: parricidio, infanticidio, asesinato atroz, exposición de personas al peligro y violación cuando la víctima sea mayor de 14 años; y en los casos que estos delitos concurran con otros, todos iban a Tribunal de Jurados.

Por Ley No. 37 de 1988, quedó establecido que ningún tipo de delito será sometido a conocimiento y veredicto de jurado. Los jueces y tribunales procederían, conforme los parámetros de 1981.

Otra reforma, al entonces Código de Instrucción Criminal, en 1993, estableció el tribunal de jurados para los delitos cuyas penas sean más que correccionales.

Durante este último período, 1981 al 2001, se presentaron diversas reformas procesales penales ${ }^{82}$ en las que se incluyeron y excluyeron del conocimiento del tribunal de jurados determinados ilícitos hasta el grado de que ningún delito fuese sometido al conocimiento del jurado, sino al de los jueces y tribunales, en base a las reglas de la sana crítica.

A partir de la vigencia del CPP, 24 diciembre 2002, todo acusado por la presunta comisión de un delito grave tiene derecho a ser juzgado por un jurado.

82 En su exposición ante el Consejo de Estado, el 28 de julio de 1982, sobre el proyecto de reformas al sistema procesal penal, el doctor Roberto Arguello Hurtado, Presidente de la Corte Suprema de Justicia, señaló, entre otras: "El tribunal de jurados tiene una incidencia en determinado sentido dentro de la administración de justicia penal. Incidencia que se caracteriza por un porcentaje muy elevado de absoluciones y por un retraso en la administración de la justicia por el incumplimiento de los jurados. Por el momento hay la decisión política de mantener la institución del jurado; y que los defectos y fallas de éste en nuestro medio obedecen al procedimiento que rige la institución, lo cual no se corregirá con las reformas propuestas.

Esta Corte, recalcaba, cree que lo que se desea no es únicamente obtener del jurado en vez de absoluciones, condenas, sino que efectivamente el jurado sea un instrumento capaz de hacer justicia para nuestro pueblo, pero con las limitaciones objetivas e institucionales actuales, el jurado no servirá para eso en Nicaragua. Estimándose que el problema fundamental lo constituye el tipo de proceso dentro del cual funciona el jurado en Nicaragua que sigue en general el viejo modelo español de dos fases: La instrucción o sumario, de carácter inquisitorio y el plenario de tipo acusatorio. Estimando que es materialmente imposible para los integrantes del tribunal de jurados formarse un juicio sereno y consciente con sólo la lectura rápida de un largo expediente, a lo que se unen factores de carácter emotivo y a los que está expuesto el jurado.

Además, señaló, que el sistema propuesto en el proyecto impide la posibilidad de que estén incluidos como jurados y por consiguiente participando en la administración de la justicia diversos sectores de la población, variando de esta forma el carácter popular democrático que teórica y jurídicamente caracterizan a esta institución". Véase “Dictamen sobre el sistema procesal”, Diario La Prensa, Managua, 29 de julio de 1982, págs. 1 y 16. 
Sin embargo, aún siendo un delito grave y estar así contemplado en el cuerpo de leyes, se exceptúan del conocimiento del jurado los delitos relacionados con el consumo o tráfico de estupefacientes, sicotrópicos y otras sustancias controladas o con lavado de dinero y activos provenientes de actividades ilícitas. Las cuales se justifican en razón de la enorme capacidad de persuasión y chantaje con la que cuentan los aparatos relacionados al crimen organizado que, en algunas ocasiones, pueden influir coactivamente en los miembros del jurado o sus familias para condicionar el veredicto que habría de pronunciarse. En cambio, a través de los medios informativos nacionales, se ha conocido de esta capacidad de persuasión del crimen organizado a algunos jueces y magistrados de los tribunales de justicia que, en algunos casos, han liberado, por medio de sentencias, a acusados por narcoactividad y devuelto a éstos los bienes ocupados que constituían las piezas de convicción.

Como nueva modalidad, y por ser un sistema garantista, se estableció que el acusado con derecho a ser juzgado por jurado puede renunciar al mismo y ser juzgado por el juez de la causa, en el plazo establecido. Esto quiere decir que la intervención del jurado en las causas penales no es obligatoria, pues se trata de un derecho potestativo del procesado, quien puede renunciar a dicho derecho y optar porque lo juzgue el juez de la causa, el cual tendrá la responsabilidad de resolver acerca de la culpabilidad del acusado y determinar lo relativo a la pena o medida de seguridad a imponer según corresponda ${ }^{83}$.

Actualmente está surgiendo una corriente reformista sobre qué delitos graves deben ser del conocimiento del jurado y cuáles no. Es decir, cuáles deben ser INCLUIDOS y cuáles deben ser EXCLUIDOS.

\section{Basan sus criterios estos reformistas, sobre la propuesta de EXCLUSION ${ }^{84}$ del sistema de jurados de más ilícitos; siendo sus opiniones, así: "Que no}

83 Barrientos Pellicer, C. R.; Vega Vargas, G. A.; Chirino Sánchez, A.; Houed Vega, M. A.; Moreno Castillo, Mª A.; Aráuz Ulloa, M. "Manual de Derecho Procesal Nicaragüense”. Valencia: Edita Tirant Lo Blanch; 2005, pág. 501.

84 En su exposición sobre la Ley de Reforma Procesal Penal, el entonces Ministro del Interior, Tomás Borge Martínez, ante el pleno del Consejo de Estado, en julio de 1982, se manifestaba sutilmente como un acérrimo adversario del jurado y un obstinado defensor de la instauración de los tribunales populares o tribunales de excepción, al señalar:" Es criterio unánime de todas las instancias estatales involucradas en esta problemática, que por ahora mientras se encuentre un sustituto más integral, el jurado deba limitarse al conocimiento de determinados delitos como el asesinato atroz y otros homicidios calificados como el parricidio, el infanticidio, la exposición de personas al peligro, el aborto y otros. Es incongruente que a estas alturas para juzgar un presunto ladrón de una cajilla de coca-colas, por ejemplo, tal como sucedió recientemente, se organice un jurado el cual después de numerosos intentos, y en este caso del ladrón de la cajilla de coca-colas fue citado 13 veces, número fatal para el pobre hombre, sólo para llegar a la conclusión de que el acusado era inocente, cuando ya había sufrido de hecho una condena superior a la que habría sufrido si lo hubiese condenado el mismo jurado. Solamente los papeles que se utilizaron en ese jurado valían más que la cajilla de coca-colas, sin señalar además el tiempo perdido de parte de los jueces, de los jurados y el tiempo perdido por el hombre que estaba preso;(...) MONEXICO Revista del Consejo de Estado, noviembre 1982, pág. 54. 


\section{Revisla de Derecho}

todos los casos deben ser examinados por los jurados, lo que acelerará la administración de justicia y reduciría costos". (MARTHA QUEZADA). "Que el sistema de jurados debía ser "guardado" hasta que supere sus niveles de analfabetismo". (SERGIO CUAREZMA). "¿Por qué Nicaragua siendo un país subdesarrollado y pobre vamos a tener sólo un sistema inquisitivo? Sería un retroceso ¿y por qué van a haber diferenciaciones entre un tipo de delitos y ciudadanos?" (WALTER CENTENO). "Para el hurto, robo, lesiones, delitos sexuales y otros de alta incidencia, sean excluidos del sistema de jurados y se resuelvan por sentencias de mero derecho, como en los casos de tráfico de drogas y lavado de dinero". (ALBA LUZ RAMOS).

Las Magistradas Quezada y Ramos, referente a la INCLUSION O EXCLUSION del conocimiento del sistema de jurados de algunos ilícitos, son del criterio de la reforma al artículo 293 CPP, para que sean EXCLUIDOS aquellos delitos que atentan contra la integridad y la vida de las personas, crimen organizado, delitos que atentan contra la paz y la seguridad pública, es decir, aluden, los graves y muy graves. Como aquellos otros de alta incidencia, tales como el hurto, robo, lesiones, delitos sexuales. Con ello, expresan, se agilizaría un poco más la gestión judicial $^{85}$.

\section{Conclusiones}

El jurado, no hay duda, ha sido una institución que jurídicamente ha estado reservada para garantizar la participación de los ciudadanos en la administración de justicia. Una de sus grandes ventajas es la de permitir el involucramiento de los ciudadanos en el juzgamiento de los delitos, alcanzando importantes objetivos de prevención general y de control del ejercicio del derecho de castigar del Estado.

$\mathrm{Al}$ aprobarse el Código Procesal Penal, por la Asamblea Nacional, trajo consigo cambios sustanciales en la realidad procesal nicaragüense: primeramente, porque conllevó al rompimiento de un sistema violatorio de los derechos humanos que regía desde 1879 caracterizado por el

85 En Italia o Alemania, en donde el jurado actúa para los delitos de más de cinco o tres años de prisión, respectivamente; en Francia solo interviene en los crímenes y nunca en las contravenciones; y en Inglaterra solo se prevé para los delitos mas graves. Mientras que en España, el jurado interviene en delitos tales como el allanamiento de morada que puede estar castigado con pena de prisión de seis meses, o en el de omisión del deber del socorro, sancionado con multa de tres meses. Y, de igual modo, conoce los delitos conexos, lo que en la práctica supone un considerable e inaceptable incremento de la competencia del jurado. 
imperio del principio inquisitivo o sea, el establecimiento de un proceso penal escrito, secreto, lento e incierto en sus resultados; en segundo lugar, porque este cuerpo de leyes trajo consigo la concreción de los derechos y garantías individuales establecidos en la Constitución Política; y finalmente, por el estricto apego a los principios del debido proceso, que no son más que el respeto absoluto al conjunto de derechos y garantías que, normados por nuestra Carta Magna, tratan de garantizar la seguridad jurídica de la persona cuando ésta, por la comisión -supuestade un hecho delictivo, es obligada a someterse a un procedimiento que tiene por objeto determinar su responsabilidad en el hecho que se le imputa.

El enjuiciamiento penal por medio de jurados es una forma de garantizar la participación ciudadana en la justicia penal. Esta participación suele ser observada como parte del marco constitucional de principios que orientan una visión democrática del proceso penal. Vincula a la ciudadanía con la sentencia en asuntos criminales, sobre todo cuando los mismos ciudadanos son testigos de las dificultades de la investigación, de los obstáculos procesales para el debate de las cuestiones importantes para decidir un asunto, y de los enormes compromisos implícitos en la declaratoria de inocencia o de culpabilidad de una persona.

A pesar de ser un derecho-deber, consagrado en la Constitución, cuando un ciudadano es seleccionado como miembro de un jurado tiene el deber de ocurrir, ejercer y desempeñar la función para la cual ha sido convocado; así, mientras para el procesado el hecho de que su causa sea sometida un juicio por jurados es un derecho potestativo, para los demás ciudadanos integrar un tribunal de jurados ha quedado establecido como un deber, aunque inicialmente el constituyente no lo haya considerado así. Sin embargo, algunos ciudadanos objetan su participación en esta institución, quizás derivada del no reconocimiento a su labor cuando sirven de jurados; la falta de educación; el desinterés de las autoridades competentes en dar realce a la importancia de servir en un jurado y dar publicidad a la necesidad de que los ciudadanos sirvan en esta calidad.

Es, sin duda alguna, la sociedad nicaragüense la que, a través de los mecanismos establecidos en la ley, interviene en el proceso penal y determina cuándo el pronunciamiento de un veredicto absolutorio o condenatorio se corresponde con el ideal de justicia que el pueblo nicaragüense entiende suficiente para el aseguramiento de una convivencia social mínima. 
Uno de los grandes problemas que ofrece esta institución democrática, es la dificultad para separar las decisiones sobre un caso tomando en cuenta el sistema de valoración de la prueba denominado de "íntima convicción”, de los criterios prejuiciados a partir de bases etarias, ideológicas, de posición social, de credo político o religioso. Es en el proceso acusatorio en el cual el jurado cumple verdaderamente con el principio de inmediación procesal, ante él se presentan todos los hechos y medios probatorios, de ahí que el juicio se realice con la presencia ininterrumpida del juez, todos los miembros del jurado, en su caso la parte acusadora, el acusado y su defensor, aunque también podrán participar adicionalmente las otras partes; y en su presencia deponen los testigos, los peritos e incluso puede participar en la realización de pruebas fuera de la sala de juicios.

Si bien, el salto más importante que da el Código Procesal Penal, es precisamente haber incorporado todas las garantías del debido proceso establecidas en el artículo 34 de la Carta Magna, entre esas, el derecho del procesado a que su causa sea sometida ante jurado, en los casos que la ley determina, la que ha de culminar con un veredicto absolutorio o condenatorio emitido por dicho tribunal; es predominante la reforma a este cuerpo de leyes tendiente a la exclusión del conocimiento del jurado de aquellos ilícitos graves y muy graves o los de mayor incidencia, como terrorismo, delincuencia organizada, delitos sexuales, robo, abigeato, lesiones y otros fenómenos de la criminalidad mafiosa, deben ser conocidos por juez técnico, para garantizar en ellos el derecho a la segunda instancia sobre la valoración de la prueba. Entre esas, se alude, que el CPP dispone que el veredicto que emite el jurado es inimpugnable ${ }^{86}, \mathrm{y}$ aunque el pueblo es soberano, la misma legislación le indica que debe seguir las reglas de la sana crítica antes de emitir su veredicto, pero al no quedar registradas las deliberaciones, ese proceso lógico no puede ser controlado posteriormente como acontece en los casos conocidos por juez técnico; aceleración de la administración de justicia y aspectos económicos; aquellos ilícitos relacionados con el crimen organizado por su enorme capacidad de persuasión; y la no tolerancia para los delitos sexuales y de violencia doméstica o intrafamiliar, pues representan la forma más violenta de disminuir la libertad de las personas.

86 "Aunque se presume que en la mayoría de los casos el jurado emite un criterio apegado a las reglas de la sana critica, lo cierto es que en los casos en que valora erróneamente la prueba, los errores del veredicto se traducen o en indefensión para el imputado o en una sensación de impunidad para la víctima o la sociedad en general". PROPUESTA presentada por la Comisión Nacional de Coordinación Interinstitucional del Sistema de Justicia Penal de la República de Nicaragua, a la Comisión de Justicia y Asuntos Jurídicos de la Asamblea Nacional, para la redacción del artículo 589 del Código Penal. 
En cambio, otros sectores opinan, que al ser sometidos determinados procesos al conocimiento del tribunal de jurado, se descarga al juez de un gran número de causas; lo que permitiría ahorrar recursos y disminuir el desgaste físico e intelectual del personal a su cargo, reduciendo los índices de retardación de la justicia.

Cualesquiera reformas que se propongan, sea constitucional o a la legislación, tendiente a la exclusión del conocimiento del tribunal de jurado de determinados procesos, debe ser debidamente garantista al momento de la declaratoria de inocencia o culpabilidad de la persona por parte del juez, a fin de evitar fallos sustentados en situaciones fuertemente cuestionables.

\section{Bibliografía}

\section{Libros}

- Asamblea Nacional de la República de Nicaragua. "Ley No. 285, Ley de Estupefacientes, Sicotrópicos y Otras Sustancias Controladas; Lavado de Dinero y Activos Provenientes de Actividades Ilícitas", La Gaceta No. 69 del 15 abril 1999.

- BARRIENTOS PELLICER, César R. Crisóstomo; Vega Vargas, Gustavo Adolfo; Chirino Sánchez, Alfredo; et al. "Manual de Derecho Procesal Penal Nicaragüense”. Valencia: Edita:TIRANT LO BLANCH, 2005.

- CANALEJAS RUBIO, José. "La pena de muerte", 1914, Edición digital, Biblioteca Digital Jurídica, Universidad de Sevilla.

- CHIRINOS RIVERA, Sonia; Isabá Acuña, Eloy; et al. "El Jurado en Nicaragua: Una valoración crítica desde la perspectiva del Derecho Comparado". Managua: Imprenta UCA, 2002.

- Código de Instrucción Criminal de Nicaragua, Managua, 1956.

- Código Orgánico Procesal Penal de Venezuela. Con Ley de Reforma Parcial/2000. Conforme a la Gaceta Oficial No. 37.022 del 25 de agosto de 2000. Caracas: Editorial Sentido, 2000.

- Código de Procedimiento Civil de la República de Nicaragua. Managua: Impresiones "LA UNIVERSAL”, 2002.

- Código Procesal Penal de la República de Nicaragua, LEY No. 406/01. Managua: IMPRIMATUR Artes Gráficas, S.A., 2003.

- Constitución Política de la República de Nicaragua. Con las Reformas Constitucionales. Managua: IMPRIMATUR Artes Gráficas, 2003. 
- Corte Suprema de Justicia. Memoria del Seminario Jurídico SILVIO MAYORGA. "La Justicia en la Revolución”, Nicaragua, Mayo de 1981. México: Editorial Popular de los Trabajadores, 1981.

- CUAREZMA TERÁN, Sergio J. "Código de Instrucción Criminal. Comentado, concordado y actualizado". Managua: Editorial HISPAMER, 1997.

- DAMASKA, Mirjan R. Las Caras de la Justicia y el Poder del Estado. Análisis comparado del proceso legal. Santiago: Editorial Jurídica de Chile, 2000.

- ESGUEVA GÓMEZ, Antonio. "Las Constituciones Políticas y sus Reformas en la Historia de Nicaragua". Tomos I y II. Managua: Editorial El Parlamento, 1994.

- FLETCHER, George P. "Las víctimas ante el jurado”. Valencia: Edita: TIRANT LO BLANCH, 1997.

- GÓMEZ COLOMER, Juan-Luís. "Juicio Penal con Jurado en la España Democrática”. Colección Monografías 9. Miami, Florida: Centro para la Administración de Justicia, 2003.

- GRISHAM, John. "El Jurado". Barcelona (España): Ediciones B, S.A., 2004.

- MELÉNDEZ, Carlos. "Hernández de Córdoba. Capitán de Conquista en Nicaragua”. Colección Cultural Banco de América. Serie Histórica No. 9. Managua: Impreso en los Talleres de Editorial y Litografía "San José", S.A., 1976.

- PÉREZ CEBADERA, María-Ángeles. "Las Instrucciones al Jurado". Valencia: Edita: TIRANT LO BLANCH, 2003.

- SERRANO CALDERA, Alejandro. "Estado de Derecho y Derechos Humanos". Managua, Editorial HISPAMER, 2004.

- VALLE PASTORA, Alfonso. "Tribunal de Jurados". Managua: Impreso en los Talleres de la Imprenta Nacional, 1975.

- VILATA MENADES, Salvador. "Sobre el Jurado: Un análisis desde una perspectiva distinta”. Valencia: Editorial Práctica de Derecho, S.L., 2001.

\section{Revistas}

- ALEMÁN FLORES, Enrique. ¿Conviene o no, suprimir el Juicio de Jurado? JUSTICIA Revista del Poder Judicial, 2003 Junio; No. 28: $61-62$.

- BORge MARTÍneZ, Tomás. Puntos de vista sobre la "LEY DE REFORMA PROCESAL PENAL”. MONEXICO Revista del Consejo de Estado, 1982 Noviembre; No. 1: 51-57. 
- HERRERA, Carmen. Participación ciudadana en la administración de justicia. JUSTICIA Órgano Informativo del Poder Judicial de Nicaragua, 1996 Febrero-Marzo; No. 5: 13-16.

- SOLÍS ROMERO, Jaime Alfonso. Cristianismo vs. Jurado de Conciencia. JUSTICIA Revista del Poder Judicial, 2005 Enero; No. 32: 121.

- RUIZ, Mario. Comentarios a la "LEY DE REFORMA PROCESAL PENAL”. MONEXICO Revista del Consejo de Estado, 1983 Abril; No. 2: 36-37.

- ARGUELLO HURTADO, Roberto. Puntos de vista sobre "LA LEY DE REFORMA PROCESAL PENAL". MONEXICO Revista del Consejo de Estado, 1982 Noviembre; No. 1: 40-49.

- La Junta de Gobierno de Reconstrucción Nacional de Nicaragua. "LEY DE PARTIDOS POLITICOS". Decreto No. 1312. MONEXICO Revista del Consejo de Estado, 1984 Enero; No. 4: 24-35.

\section{Internet}

- El Tribunal del Jurado, España, 28 junio 2006, http://www.sc.ehu. es/dpwlonaa/legislación/CUESTIONES\%20PRACT.\%20DE\% 2OINT...

- Juicio por Jurados, Mar del Plata, Argentina, 29 junio 2006, http:// www.psicofxp.com/forums/1782698-post1.htm1

- Juicio por Jurados; Trabajo realizado por profesores y alumnos de segundo año del post-grado en Derecho Procesal de la Universidad del Salvador, Provincia de Entre Ríos, Argentina, 29 junio 2006, http:// www.salvador.edu.ar/ua1-jxj.htm

\section{Periódicos}

- Diario “La Prensa”. Managua, publicaciones del 9 de marzo,1991; 8 de octubre, 2004; 7 de agosto,2006; 25 de octubre, 2006; 5 de febrero, 2007; 13 de abril, 2007; 22 de mayo, 2007; y, 23 de mayo, 2007.

- El Nuevo Diario. Managua, publicaciones del 9 de marzo, 1991; 6 de octubre, 2004; 5 de agosto, 2006; 6 de agosto, 2006; 31 de agosto, 2006; 17 de abril, 2007; 22 de mayo, 2007; y, 22 de junio, 2007.

- Diario "Barricada". Managua, publicaciones del 22 de agosto, 1990; y, 8 de marzo, 1991. 